\title{
Effects of Fucoidans from Five Different Brown Algae on Oxidative Stress and VEGF Interference in Ocular Cells
}

\author{
Philipp Dörschmann ${ }^{1}$, Kaya Saskia Bittkau ${ }^{2}$, Sandesh Neupane ${ }^{2}$, Johann Roider ${ }^{1}$, \\ Susanne Alban ${ }^{2}$ and Alexa Klettner ${ }^{1, *}$ \\ 1 Department of Ophthalmology, University Medical Center, University of Kiel, Arnold-Heller-Str. 3, Haus 25, \\ 24105 Kiel, Germany; Philipp.Doerschmann@uksh.de (P.D.); johann.roider@uksh.de (J.R.) \\ 2 Department of Pharmaceutical Biology, Pharmaceutical Institute, University of Kiel, Gutenbergstraße 76, \\ 24118 Kiel, Germany; kbittkau@pharmazie.uni-kiel.de (K.S.B.); sneupane@pharmazie.uni-kiel.de (S.N.); \\ salban@pharmazie.uni-kiel.de (S.A.) \\ * Correspondence: alexakarina.klettner@uksh.de; Tel.: +49-431-500-24283
}

Received: 20 March 2019; Accepted: 25 April 2019; Published: 30 April 2019

\begin{abstract}
Background: Fucoidans are interesting for potential usage in ophthalmology, and especially age-related macular degeneration. However, fucoidans from different species may vary in their effects. Here, we compare fucoidans from five algal species in terms of oxidative stress protection and vascular endothelial growth factor (VEGF) interference in ocular cells. Methods: Brown algae (Fucus vesiculosus, Fucus distichus subsp. evanescens, Fucus serratus, Laminaria digitata, Saccharina latissima) were harvested and fucoidans isolated by hot-water extraction. Fucoidans were tested in several concentrations $(1,10,50$, and $100 \mu \mathrm{g} / \mathrm{mL})$. Effects were measured on a uveal melanoma cell line (OMM-1) (oxidative stress), retinal pigment epithelium (RPE) cell line ARPE19 (oxidative stress and VEGF), and primary RPE cells (VEGF). Oxidative stress was induced by $\mathrm{H}_{2} \mathrm{O}_{2}$ or tert-Butyl hydroperoxide (TBHP). Cell viability was investigated with methyl thiazolyl tetrazolium (MTT or MTS) assay, and VEGF secretion with ELISA. Affinity to VEGF was determined by a competitive binding assay. Results: All fucoidans protected OMM-1 from oxidative stress. However, in ARPE19, only fucoidan from Saccharina latissima was protective. The affinity to VEGF of all fucoidans was stronger than that of heparin, and all reduced VEGF secretion in ARPE19. In primary RPE, only the fucoidan from Saccharina latissima was effective. Conclusion: Among the fucoidans from five different species, Saccharina latissima displayed the most promising results concerning oxidative stress protection and reduction of VEGF secretion.
\end{abstract}

Keywords: fucoidan; age-related macular degeneration; VEGF; oxidative stress; Saccharina latissima; Fucus vesiculosus; Fucus distichus subsp. evanescens; Fucus serratus; Laminaria digitata

\section{Introduction}

Fucoidans are sulfated polysaccharides found in the cell walls of brown algae. Common to all fucoidans is a high amount of L-fucose, yet their structures are complex and variable among different species [1]. Fucoidans have been described as exerting interesting pharmacological activities including, e.g., anti-inflammatory, antitumorigenic, and anti-angiogenic effects [1,2]. In particular, a fucoidan has been found to be potentially beneficial in age-related macular degeneration (AMD), the most common cause of blindness and severe vision loss in the Western world [3,4]. AMD is a disease of the elderly in which photoreceptors and retinal pigment epithelial cells of the macula, the area of high acuity vision, degenerate, and, in the more severe exudative subtype of the disease (wet AMD), vessels grow from the choroid under and into the retina. These immature vessels are leaky and lead to fluid 
accumulation and tissue destruction. The pathogenesis of AMD is complex and not fully elucidated. It is a multifactorial disease and several factors are involved in its pathogenesis. The most important ones are oxidative stress and, in wet AMD, the secretion of vascular endothelial growth factor (VEGF) by cells of the retinal pigment epithelium (RPE) [5-7]. Other factors such as impaired complement regulation, lipid dysregulation, and inflammation are also of importance for AMD development [8-10]. Currently, there is no cure for AMD, and the only treatment options are VEGF inhibitors, which need to be regularly injected in the eye [11]. Although these inhibitors have been a great progress in AMD therapy, long-term treatment usually cannot keep up the initial beneficial effects, and may lead to macular atrophy $[12,13]$. New treatment options would, therefore, be of great benefit.

Fucoidan could be of interest for the development of new AMD therapeutics, since it has been described to be anti-inflammatory, blood lipid-reducing and, most importantly, protective against oxidative stress and VEGF-inhibiting [4].

Our group has previously shown that commercially available fucoidan (from Fucus vesiculosus) exhibits interesting effects on RPE cells including reduction of VEGF secretion and reduction of angiogenesis [3]. However, the commercially available fucoidan is poorly defined, with pronounced variability in structural composition and degree of purity between batches [14,15]. Furthermore, fucoidans from different species differ in their composition and may thus exert different biological effects. This renders the search for the most suitable fucoidan for specific applications such as AMD an important quest $[4,16]$.

In the current study, we compared the fucoidans of five species of brown algae (Saccharina latissima (SL), Laminaria digitata (LD), Fucus serratus (FS), Fucus vesiculosus (FV), and Fucus distichus subsp. evanescens (FE) in terms of two important factors for AMD development, i.e., oxidative stress and VEGF secretion in ocular cells, as well as their binding affinity to VEGF. For this comparison, the algal material of all five species were harvested in summer, identically prepared, and then extracted according to the same standardized protocol, leading to the fucoidans SL, LD, FS, FV, and FE.

\section{Results}

\subsection{Oxidative Stress Protection}

\subsubsection{OMM-1 Cells}

The potency of oxidative stress protection of the fucoidan from five different algae species was compared in two different systems. We have previously shown that commercial fucoidan from Fucus vesiculosus protected several uveal melanoma cells, including OMM-1, from oxidative stress induced by $\mathrm{H}_{2} \mathrm{O}_{2}$ [17]. In this study, we used the uveal melanoma cell line OMM-1.

Prior to the experiments with fucoidans, the concentration of $\mathrm{H}_{2} \mathrm{O}_{2}$ causing about $50 \%$ cell death had to be evaluated. While the concentrations of $100 \mu \mathrm{M}(78.67 \pm 13.22 \%), 200 \mu \mathrm{M}(85.67 \pm 17.02 \%)$ and $400 \mu \mathrm{M}(81.00 \pm 15.51 \%)$ showed no effect on cell survival, $1000 \mu \mathrm{M}$ displayed a significant reduction of cell viability compared to the control $(1000 \mu \mathrm{M} 58.33 \pm 17.98 \%, p<0.05)$ (Figure 1a). A concentration of $1000 \mu \mathrm{M} \mathrm{H}_{2} \mathrm{O}_{2}$ was therefore chosen for the following experiments.
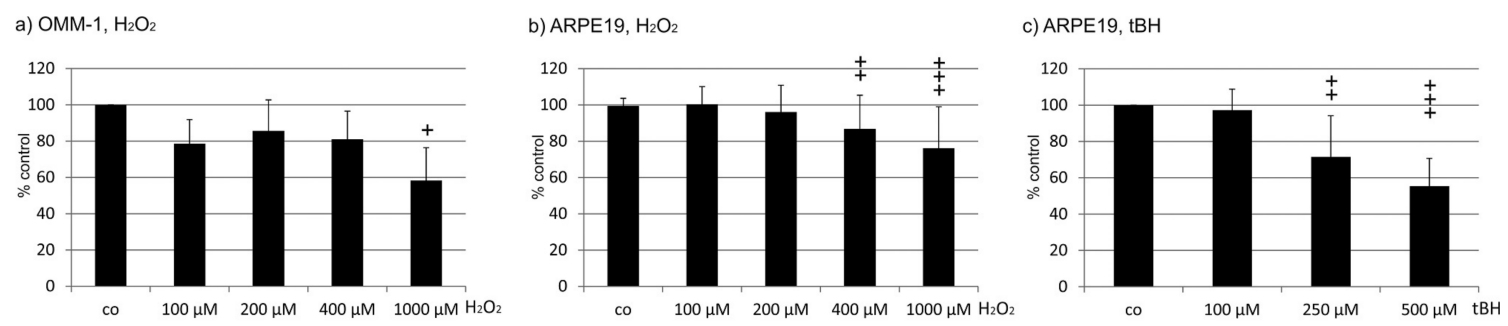

Figure 1. Characterization of the susceptibility of cell lines to oxidative stress. Cell viability was tested in OMM-1 (a) and ARPE19 (b) exposed to $\mathrm{H}_{2} \mathrm{O}_{2}(\mathbf{a}, \mathbf{b})$ and tert-Butyl hydroperoxide (TBHP) (c). Significance was evaluated with Friedman's ANOVA and Student's $t$-test, $+p<0.05,++p<0.01,+++$ $p<0.001$ compared to control $(n>3)$. 
In the experiments concerning the fucoidan from Saccharina latissima, incubation of OMM-1 treated with $1 \mathrm{mM} \mathrm{H}_{2} \mathrm{O}_{2}$ and SL fucoidan induced significant changes according to ANOVA testing. Incubation with $1 \mathrm{mM} \mathrm{H}_{2} \mathrm{O}_{2}$ resulted in a reduction of cell viability to $68.75 \%( \pm 5.07)$. Incubation with $1 \mu \mathrm{g} / \mathrm{mL}$ induced no significant protection $(72.00 \pm 3.04 \%$ ), while $10 \mu \mathrm{g} / \mathrm{mL}, 50 \mu \mathrm{g} / \mathrm{mL}$, as well as $100 \mu \mathrm{g} / \mathrm{mL}$ all significantly increased cell viability $(92.13 \pm 3.41 \%$; $93.00 \pm 3.57 \%$, and $85.88 \pm 7.03 \%$, respectively; all $p<0.001$ ) (Figure 2a). In the experiments testing fucoidan from Laminaria digitata, incubation with $1 \mathrm{mM} \mathrm{H}_{2} \mathrm{O}_{2}$ reduced cell viability to $57.50 \%( \pm 2.29)$. The differences between the groups treated with LD fucoidan were significant in ANOVA testing. Incubations with any concentration of LD fucoidan tested resulted in a highly significant protection of cell viability (all $p<0.001)(1 \mu \mathrm{g} / \mathrm{mL} 83.25 \pm 3.60 \%$; $10 \mu \mathrm{g} / \mathrm{mL} 101.75 \pm 4.71 \% ; 50 \mu \mathrm{g} / \mathrm{mL} 100.88 \pm 5.51 \% ; 100 \mu \mathrm{g} / \mathrm{mL} 92.75 \pm 7.03 \%$ ) (Figure 2b). Testing fucoidan from Fucus serratus, incubation with $1 \mathrm{mM} \mathrm{H}_{2} \mathrm{O}_{2}$ resulted in a reduction of cell viability to $39.00 \%$ ( \pm 3.67$)$. In ANOVA testing, significant differences between the groups could be detected. FS fucoidan increased cell viability significantly, but viability remained considerably low $(1 \mu \mathrm{g} / \mathrm{mL}$ $45.25 \pm 3.35 \%, p<0.01 ; 10 \mu \mathrm{g} / \mathrm{mL} 59.88 \pm 3.02 \%, p<0.001 ; 50 \mu \mathrm{g} / \mathrm{mL} 58.63 \pm 5.10 \%, p<0.001 ; 100 \mu \mathrm{g} / \mathrm{mL}$ $52.38 \pm 5.87 \% p<0.001$ ) (Figure 2c). When testing the fucoidan from Fucus vesiculosus, incubation with $1 \mathrm{mM} \mathrm{H}_{2} \mathrm{O}_{2}$ resulted in a reduction of cell viability to $63.50 \%( \pm 2.60)$. In ANOVA testing, significant differences between the groups could be detected. All concentrations of FV fucoidan resulted in a significantly increased viability of cells $(1 \mu \mathrm{g} / \mathrm{mL} 75.75 \pm 10.50 \%, p<0.01 ; 10 \mu \mathrm{g} / \mathrm{mL} 97.88 \pm 14.93 \%$, $p<0.001 ; 50 \mu \mathrm{g} / \mathrm{mL} 96.36 \pm 13.30 \%, p<0.001 ; 100 \mu \mathrm{g} / \mathrm{mL} 87.88 \pm 11.13 \%, p<0.001$ ) (Figure 2d). Finally, when testing the fucoidan from Fucus distichus subsp. evanescens, incubation with $1 \mathrm{mM} \mathrm{H}_{2} \mathrm{O}_{2}$ resulted in a reduction of cell viability to $36.50 \%( \pm 8.44)$. In ANOVA testing, significant differences between the groups could be detected. FE fucoidan significantly increased viability when used at $1-50 \mu \mathrm{g} / \mathrm{mL}$ $(1 \mu \mathrm{g} / \mathrm{mL} 54.38 \pm 18.00 \%, p<0.05: 10 \mu \mathrm{g} / \mathrm{mL} 69.5 \pm 17.43 \%, p<0.001 ; 50 \mu \mathrm{g} / \mathrm{mL} 62.00 \pm 18.10 \%, p<0.01)$ but not at $100 \mu \mathrm{g} / \mathrm{mL}(55.00 \pm 22.63 \%)$ (Figure 2e).

Taken together, all fucoidans were protective against oxidative stress-induced reduction of viability, and all showed a similar pattern, with the highest viability rates at 10 and $50 \mu \mathrm{g} / \mathrm{mL}$. However, the fucoidans displayed significant differences when their effects were compared. LD fucoidan clearly showed the strongest protective effect, which was significantly higher than that of SL (for 1 and $10 \mu \mathrm{g} / \mathrm{mL} p<0.001 ; 50 \mu \mathrm{g} / \mathrm{mL} p<0.001)$, significantly higher than that of $\mathrm{FE}(1 \mu \mathrm{g} / \mathrm{mL} p<0.01$; $10-100 \mu \mathrm{g} / \mathrm{mL} p<0.001$ ), and significantly higher than FS (all $p<0.001$ ). FV was significantly more effective than FE $(1 \mu \mathrm{g} / \mathrm{mL} p<0.05 ; 10-100 \mu \mathrm{g} / \mathrm{mL} p<0.01)$ and significantly more effective than FS (all $p<0.001)$. Finally, SL was significantly more protective than FE $(1 \mu \mathrm{g} / \mathrm{mL} p<0.05 ; 10 \mu \mathrm{g} / \mathrm{mL}$ $p<0.01 ; 50 \mu \mathrm{g} / \mathrm{mL} p<0.001 ; 100 \mu \mathrm{g} / \mathrm{mL} p<0.01$ ) and more protective than FS (all $p<0.001$ ). FE and FS, however, displayed no statistically significant differences (Table 1). Ranging the protective effect, $\mathrm{LD}>\mathrm{FV}>\mathrm{SL}>\mathrm{FE}>\mathrm{FS}$.

Table 1. Comparison of the protective effects of the different fucoidans at different concentrations against oxidative stress cell death in OMM-1 cells induced with $1 \mathrm{mM} \mathrm{H}_{2} \mathrm{O}_{2}$.

\begin{tabular}{ccccc}
\hline Compared Fucoidans & $\mathbf{1} \boldsymbol{\mu g} / \mathbf{m L}$ & $\mathbf{1 0} \boldsymbol{\mu g} / \mathbf{m L}$ & $\mathbf{5 0} \boldsymbol{\mu g} / \mathbf{m L}$ & $\mathbf{1 0 0} \boldsymbol{\mu g} / \mathbf{m L}$ \\
\hline LD vs. FV & not significant (ns) & $\mathrm{ns}$ & $\mathrm{ns}$ & $\mathrm{ns}$ \\
LD vs. SL & $p<0.001$ & $p<0.001$ & $p<0.01$ & $\mathrm{~ns}$ \\
LD vs. FE & $p<0.05$ & $p<0.001$ & $p<0.001$ & $p<0.001$ \\
LD vs. FS & $p<0.001$ & $p<0.001$ & $p<0.001$ & $p<0.001$ \\
FV vs. SL & $\mathrm{ns}$ & $\mathrm{ns}$ & $\mathrm{ns}$ & $\mathrm{ns}$ \\
FV vs. FE & $p<0.05$ & $p<0.01$ & $p<0.01$ & $p<0.01$ \\
FV vs. FS & $p<0.001$ & $p<0.001$ & $p<0.001$ & $p<0.001$ \\
SL vs. FE & $p<0.05$ & $p<0.01$ & $p<0.001$ & $p<0.01$ \\
SL vs. FS & $p<0.001$ & $p<0.001$ & $p<0.001$ & $p<0.001$ \\
FE vs. FS & $\mathrm{ns}$ & $\mathrm{ns}$ & $\mathrm{ns}$ & $\mathrm{ns}$ \\
\hline
\end{tabular}



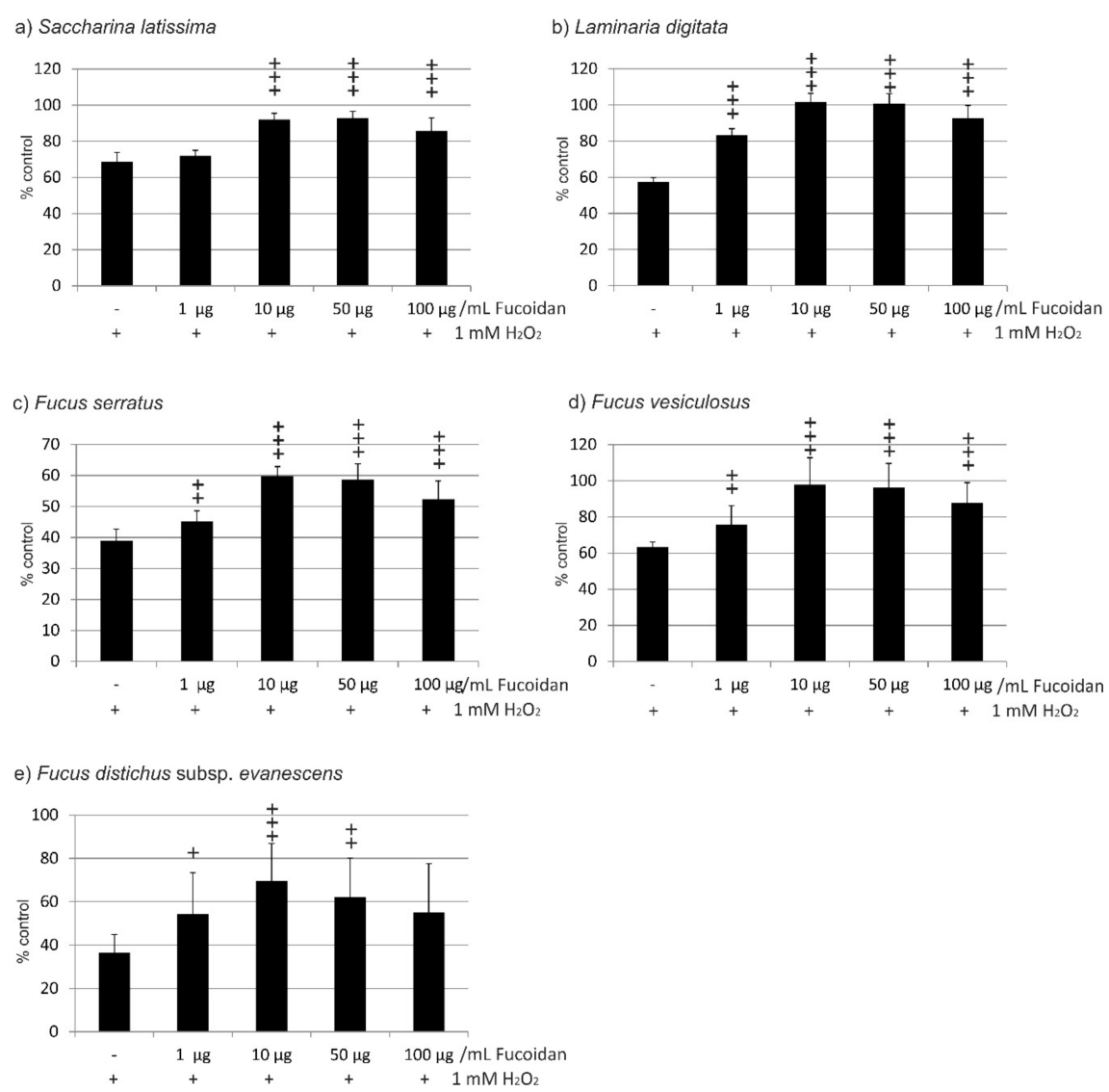

Figure 2. Cell viability of OMM-1 cells challenged with $1 \mathrm{mM} \mathrm{H}_{2} \mathrm{O}_{2}$ after incubation with fucoidan from (a) Saccharina latissima (SL), (b) Laminaria digitata (LD), (c) Fucus serratus (FS), (d) Fucus vesiculosus (FV), (e) Fucus distichus subsp. evanescens (FE). Cell viability was measured by MTS assay and is depicted as mean and standard deviation, with the control set as 100\%. All fucoidans tested displayed protective effects, with the efficacy of LD $>$ FV $>$ SL $>$ FE $>$ FS. Significance was evaluated with Friedman's ANOVA and subsequent Student's $t$-test, $+p<0.05,++p<0.01,+++p<0.001$, all versus $1 \mathrm{mM} \mathrm{H}_{2} \mathrm{O}_{2}(n=8)$.

\subsubsection{ARPE19 Cells}

ARPE19 cells are an immortal RPE cell line. One important role of RPE cells is protection against oxidative stress [18]. We tested the appropriate concentration of $\mathrm{H}_{2} \mathrm{O}_{2}$ for the following experiments, but ARPE19 cells turned out to be rather resistant to oxidative stress induced by hydrogen peroxide, which is consistent with the literature [19]. Treatment with $\mathrm{H}_{2} \mathrm{O}_{2}$ induced a significant reduction in cell viability, detected in ANOVA. While incubation with 100 and $200 \mu \mathrm{M} \mathrm{H}_{2} \mathrm{O}_{2}$ did not induce any significant reduction in cell viability compared to the control $(100 \mu \mathrm{M} 11.45 \pm 9.65 \% ; 200 \mu \mathrm{M} 96.07 \pm 14.75 \%), 400$ and $1000 \mu \mathrm{M} \mathrm{H}_{2} \mathrm{O}_{2}$ significantly reduced cell survival $(400 \mu \mathrm{M} 86.75 \pm 18.62 \%, p<0.01 ; 1000 \mu \mathrm{M} 76.2 \pm 22.74 \%$, $p<0.001$ ). However, none of these concentrations reduced cell survival to approximately $50 \%$ (Figure $1 \mathrm{~b}$ ). We then tested tert-Butyl hydroperoxide (TBHP) on ARPE19 cells, which induced a significant reduction in cell viability (detected in ANOVA) and showed a concentration-dependent effect with a significant reduction of cell viability at $500 \mu \mathrm{M}(100 \mu \mathrm{M} 97.24 \pm 11.56 \%, 250 \mu \mathrm{M} \pm 22.66 \% ; 500 \mu \mathrm{M} 55.33 \pm 15.3 \%)$ (Figure 1c). Therefore, for the following experiments, a concentration of $500 \mu \mathrm{M}$ TBHP was chosen.

In the experiments concerning the fucoidan of Saccharina latissima, incubation with $500 \mu \mathrm{g} / \mathrm{mL}$ TBHP induced a reduction in cell viability to $48.50 \pm 8.44 \%$. ANOVA testing showed significant differences between the groups. Incubation with $1 \mu \mathrm{g} / \mathrm{mL}$ induced no significant protection $(55.63 \pm 14.48 \%)$, while $10 \mu \mathrm{g} / \mathrm{mL}, 50 \mu \mathrm{g} / \mathrm{mL}$, and $100 \mu \mathrm{g} / \mathrm{mL}$ significantly increased cell viability $(71.50 \pm 13.37 \%$, $p<0.01 ; 73.25 \pm 12.59 \%, p<0.001 ; 64.00 \pm 9.46 \%, p<0.01$ ) (Figure 3a). In the experiments testing fucoidan from Laminaria digitata, incubation with $500 \mu \mathrm{g} / \mathrm{mL}$ TBHP induced a reduction in cell viability 
to $75.50 \pm 8.20 \%$. ANOVA testing showed statistically significant differences between the groups. However, none of the administered concentrations of fucoidan protected the cells against loss of cell viability $(1 \mu \mathrm{g} / \mathrm{mL} 77.88 \pm 10.40 \% ; 10 \mu \mathrm{g} / \mathrm{mL} 79.38 \pm 11.33 \% ; 50 \mu \mathrm{g} / \mathrm{mL} 77.75 \pm 12.94 \% ; 100 \mu \mathrm{g} / \mathrm{mL}$ $72.50 \pm 16.55 \%$ ) (Figure 3b). Testing fucoidan from Fucus serratus, incubation with $500 \mu \mathrm{M}$ TBHP resulted in a reduction of cell viability to $58.00 \%( \pm 3.24)$. ANOVA testing showed statistically significant differences between the groups. Again, none of the tested concentrations of FS fucoidan conferred any protection. On the contrary, $10-100 \mu \mathrm{g} / \mathrm{mL}$ FS fucoidan significantly reduced the viability of the cells $(1 \mu \mathrm{g} / \mathrm{mL} 54.50 \pm 4.21 \% ; 10 \mu \mathrm{g} / \mathrm{mL} 53.13 \pm 3.18 \%, p<0.05 ; 50 \mu \mathrm{g} / \mathrm{mL} 51.75 \pm 3.56 \%, p<0.01 ; 100 \mu \mathrm{g} / \mathrm{mL}$ $44.88 \pm 6.27 \% . p<0.001$ ) (Figure 3c). When testing for fucoidan from Fucus vesiculosus, incubation with $500 \mathrm{mM}$ TBHP resulted in a reduction of cell viability to $62.00 \%( \pm 15.86)$. ANOVA testing showed statistically significant differences between groups. However, none of the tested concentrations of FV fucoidan induced a significant change in cell viability $(1 \mu \mathrm{g} / \mathrm{mL} 70.88 \pm 16.80 \% ; 10 \mu \mathrm{g} / \mathrm{mL} 75.38$ $\pm 16.43 \% ; 50 \mu \mathrm{g} / \mathrm{mL} 77.50 \pm 18.4 \% ; 69.75 \pm 17.69 \%$ ) (Figure 3d). Finally, when testing fucoidan from Fucus distichus subsp. evanescens, incubation with $500 \mathrm{mM}$ TBHP resulted in a reduction of cell viability to $63.50 \%( \pm 4.33)$. ANOVA testing showed statistically significant differences between groups. While FE fucoidan in concentrations of $1 \mu \mathrm{g} / \mathrm{mL}(61.00 \pm 3.08 \%)$ and $10 \mu \mathrm{g} / \mathrm{mL}(61.50 \pm 4.06 \%)$ displayed no influence on cell viability, both $50 \mu \mathrm{g} / \mathrm{mL}$ and $100 \mu \mathrm{g} / \mathrm{mL}$ FE fucoidan significantly reduced cell viability (50 $\mathrm{gg} / \mathrm{mL} 49.38 \pm 4.99 \% ; 100 \mu \mathrm{g} / \mathrm{mL} 45.00 \pm 5.15 \%$; both $p<0.001)$ (Figure $3 \mathrm{e}$ ).
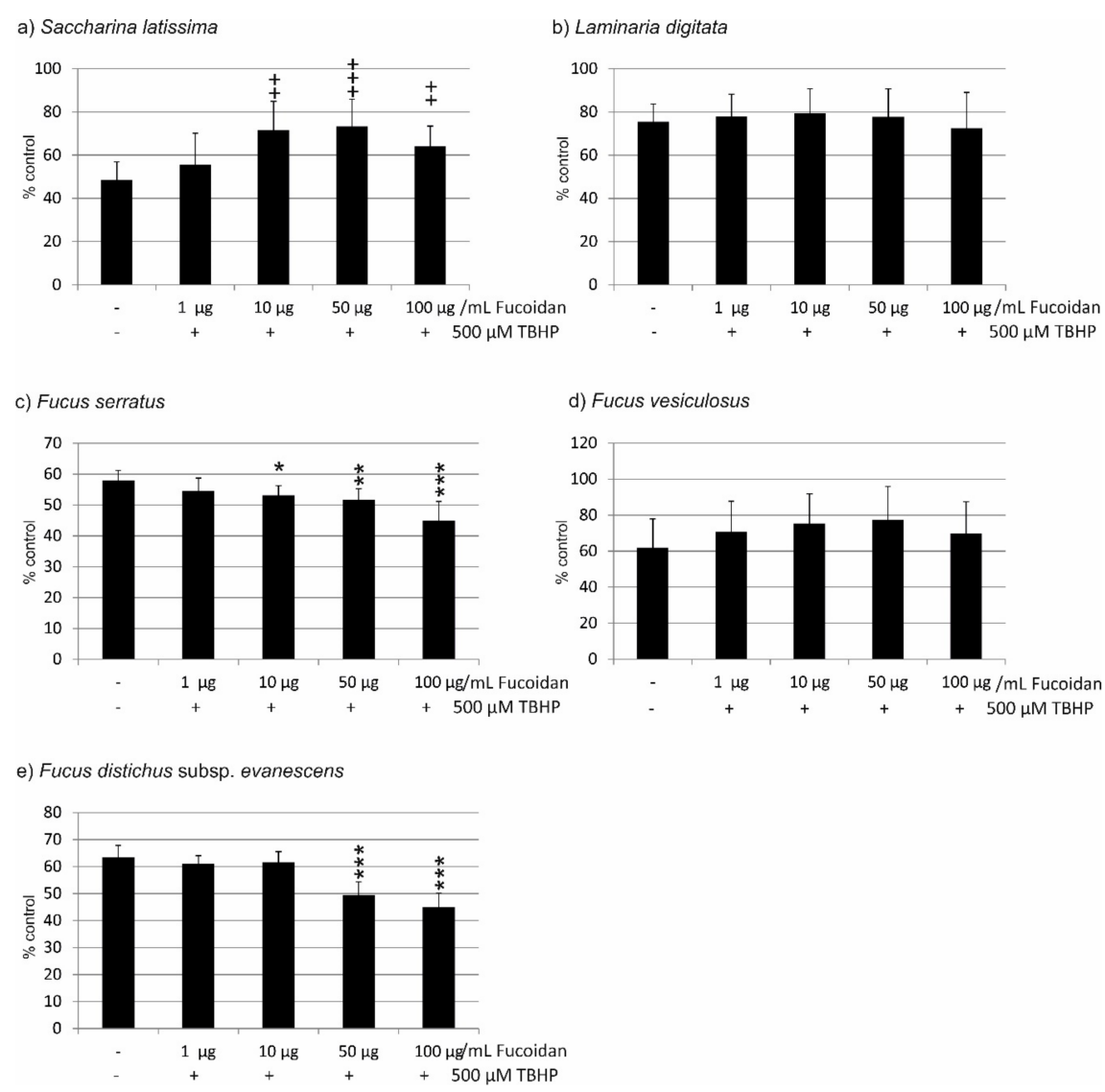

Figure 3. Cell viability of ARPE19 cells challenged with $500 \mu \mathrm{M}$ TBHP after incubation with fucoidan from (a) Saccharina latissima (SL), (b) Laminaria digitata (LD), (c) Fucus serratus (FS), (d) Fucus vesiculosus (FV), (e) Fucus distichus subsp. evanescens (FE). Cell viability was measured by MTS assay and is depicted as mean and standard deviation, with the control set as 100\%. Only SL fucoidan displayed a protective effect, while FS and FE fucoidans reduced cell viability. Significance was evaluated with Friedman's ANOVA and subsequent Student's $t$-test, $++p<0.01,+++p<0.001$, for protective effects against $500 \mu \mathrm{M} \mathrm{TBHP},{ }^{*} p<0.05,{ }^{* *} p<0.01$ and ${ }^{* * *} p<0.001$ for exacerbating effects against $500 \mu \mathrm{M}$ TBHP $(n=8)$. 
Taken together, the results differ profoundly from those found with OMM-1 cells, with only Saccharina latissima showing protection, Laminaria digitata and Fucus vesiculosus displaying no influence, and Fucus serratus and Fucus distichus subsp. evanescens showing an additional toxic effect on the cells.

In direct comparison, SL fucoidan is significantly different from LD fucoidan $(1 \mu \mathrm{g} / \mathrm{mL} ; p<0.01)$, from FS fucoidan $(10 \mu \mathrm{g} / \mathrm{mL}(p<0.01)-100 \mu \mathrm{g} / \mathrm{mL}(p<0.001)$, and from FE fucoidan $(50 \mu \mathrm{g} / \mathrm{mL}$ and $100 \mu \mathrm{g} / \mathrm{mL}$, both $p<0.001$ ). The differences between SD fucoidan and FV fucoidan are not significant. Similar results are obtained with LD fucoidan, which does not significantly differ from FV fucoidan, but does differ from FE fucoidan and FS fucoidan in all concentrations tested (FE: 1-10 $\mu \mathrm{g} / \mathrm{mL} p<0.01$, 50-100 $\mu \mathrm{g} / \mathrm{mL} p<0.001$; FS $1-50 \mu \mathrm{g} / \mathrm{mL} p<0.001,100 \mu \mathrm{g} / \mathrm{mL} p<0.01)$. FV fucoidan differs from FE fucoidan at $10-100 \mu \mathrm{g} / \mathrm{mL}(10 \mu \mathrm{g} / \mathrm{mL} p<0.05 ; 50-100 \mu \mathrm{g} / \mathrm{mL} p<0.01)$ and from FS fucoidan at all concentrations $(1 \mu \mathrm{g} / \mathrm{mL} p<0.05,10-100 \mu \mathrm{g} / \mathrm{mL} p<0.01)$. FE fucoidan differs from FS fucoidan in the lower concentrations $(1 \mu \mathrm{g} / \mathrm{mL} p<0.01,10 \mu \mathrm{g} / \mathrm{mL} p<0.001)$ (Table 2).

Table 2. Comparison of the protective effects of the different fucoidans at different concentrations after oxidative stress cell death in ARPE19 cells induced by $500 \mu \mathrm{M}$ TBHP.

\begin{tabular}{ccccc}
\hline Compared Fucoidans & $\mathbf{1} \boldsymbol{\mu g} / \mathbf{m L}$ & $\mathbf{1 0} \boldsymbol{\mu g} / \mathbf{m L}$ & $\mathbf{5 0} \boldsymbol{\mu g} / \mathbf{m L}$ & $\mathbf{1 0 0} \boldsymbol{\mu g} / \mathbf{m L}$ \\
\hline LD vs. FV & $\mathrm{ns}$ & $\mathrm{ns}$ & $\mathrm{ns}$ & $\mathrm{ns}$ \\
LD vs. SL & $p<0.01$ & $\mathrm{~ns}$ & $\mathrm{~ns}$ & $\mathrm{~ns}$ \\
LD vs. FE & $p<0.01$ & $p<0.01$ & $p<0.001$ & $p<0.001$ \\
LD vs. FS & $p<0.001$ & $p<0.001$ & $p<0.001$ & $p<0.01$ \\
FV vs. SL & $\mathrm{ns}$ & $\mathrm{ns}$ & $\mathrm{ns}$ & $\mathrm{ns}$ \\
FV vs. FE & $\mathrm{ns}$ & $p<0.05$ & $p<0.01$ & $p<0.01$ \\
FV vs. FS & $p<0.05$ & $p<0.01$ & $p<0.01$ & $p<0.01$ \\
SL vs. FE & $\mathrm{ns}$ & $\mathrm{ns}$ & $p<0.001$ & $p<0.001$ \\
SL vs. FS & $\mathrm{ns}$ & $p<0.01$ & $p<0.001$ & $p<0.001$ \\
FE vs. FS & $p<0.01$ & $p<0.001$ & $\mathrm{~ns}$ & $\mathrm{~ns}$ \\
\hline
\end{tabular}

\subsection{VEGF Secretion}

The effect of the five different fucoidans on the secretion of VEGF was compared in two different RPE cell types, the human cell line ARPE19 and primary RPE cells derived from porcine eyes. Untreated ARPE19 cells secreted considerably and significantly less VEGF, with a mean of $416.33 \mathrm{pg} / \mathrm{mL}$ $( \pm 415.27)$, in a collection time of $24 \mathrm{~h}$ compared to primary porcine RPE cells, which secreted a mean of $2386.88 \mathrm{pg} / \mathrm{mL}( \pm 824.81)(p<0.001)$ in a collection time of $4 \mathrm{~h}$, as tested in ANOVA and subsequent $t$-test.

\subsubsection{ARPE19}

Before testing the five fucoidan extracts, we established the parameters for this test with commercially available fucoidan from Fucus vesiculosus (Sigma) with both ARPE19 cells and primary RPE cells (see below). Sigma fucoidan was applied to the cells and supernatant was harvested after 1 day, 3 days, and 7 days. After 7 days, the experiment was terminated and cell viability was measured. Using Sigma fucoidan on ARPE19 cells for one day, no statistical difference could be found in ANOVA $(1 \mu \mathrm{g} / \mathrm{mL} 82.13 \pm 33.16 \% ; 10 \mu \mathrm{g} / \mathrm{mL} 79.13 \pm 27.21 \% ; 50 \mu \mathrm{g} / \mathrm{mL} 72.25 \pm 43.1 \% ; 100 \mu \mathrm{g} / \mathrm{mL} 89.13 \pm 45.02 \%)$. After 3 days of incubation, a strong VEGF reduction could be seen, which was significant in ANOVA and was significant at concentrations of $50 \mu \mathrm{g} / \mathrm{mL}$ and $100 \mu \mathrm{g} / \mathrm{mL}$ in further testing $(1 \mu \mathrm{g} / \mathrm{mL} 110.83$ $\pm 35.94 \% ; 10 \mu \mathrm{g} / \mathrm{mL} 71.83 \pm 52.07 \% ; 50 \mu \mathrm{g} / \mathrm{mL} 63.83 \pm 34.62 \%, p<0.05 ; 100 \mu \mathrm{g} / \mathrm{mL} 50.33 \pm 37.33 \%$, $p<0.05 ;$ day $7: 1 \mu \mathrm{g} / \mathrm{mL} 120 \pm 79.39 \% ; 10 \mu \mathrm{g} / \mathrm{mL} 105.00 \pm 83.01 \% ; 50 \mu \mathrm{g} / \mathrm{mL} 93.83 \pm 69.61 \% ; 100 \mu \mathrm{g} / \mathrm{mL}$ $56.83 \pm 50.33 \%$ ) (Figure 4 a). In addition, we tested the effect of heparin as a known VEGF-binding control compound. At all days, a significant reduction could be detected in ANOVA testing. At the first day, a significant reduction was found for a concentration of $100 \mu \mathrm{g} / \mathrm{mL}$ heparin $(1 \mu \mathrm{g} / \mathrm{mL} 84.25$ $\pm 37.56 \% ; 10 \mu \mathrm{g} / \mathrm{mL} 96.50 \pm 40.33 \% ; 50 \mu \mathrm{g} / \mathrm{mL} 67.50 \pm 58.41 \% ; 100 \mu \mathrm{g} / \mathrm{mL} 44.13 \pm 20.18 \%, p<0.001)$. For day 3 and day 7 , both $50 \mu \mathrm{g} / \mathrm{mL}$ and $100 \mu \mathrm{g} / \mathrm{mL}$ displayed a significant reduction of VEGF (day 3 : $1 \mu \mathrm{g} / \mathrm{mL} 94.17 \pm 61.81 \% ; 10 \mathrm{~g} / \mathrm{ml} 59.50 \pm 40.01 \% ; 50 \mu \mathrm{g} / \mathrm{mL} 43.50 \pm 28.39 \%, p<0.01 ; 100 \mu \mathrm{g} / \mathrm{mL} 24.50 \pm$ $26.30 \%, p<0.001$; day $7: 1 \mu \mathrm{g} / \mathrm{mL} 112.33 \pm 79.45 \% ; 10 \mu \mathrm{g} / \mathrm{mL} 77.67 \pm 70.13 \% ; 50 \mu \mathrm{g} / \mathrm{mL} 36.83 \pm 40.01 \%$, 
$p<0.01 ; 100 \mu \mathrm{g} / \mathrm{mL} 17.17 \pm 34.40 \%, p<0.001$ ) (Figure $4 \mathrm{~b}$ ). No significant reduction in cell viability could be detected after 7 days $(1 \mu \mathrm{g} / \mathrm{mL} 148.17 \pm 37.12 \% ; 10 \mu \mathrm{g} / \mathrm{mL} 127.00 \pm 20.98 \% ; 50 \mu \mathrm{g} / \mathrm{mL} 101.00 \pm$ $21.93 \% ; 100 \mu \mathrm{g} / \mathrm{mL} 78.83 \pm 28.11 \%$ ) (Figure $4 \mathrm{c}$ ).

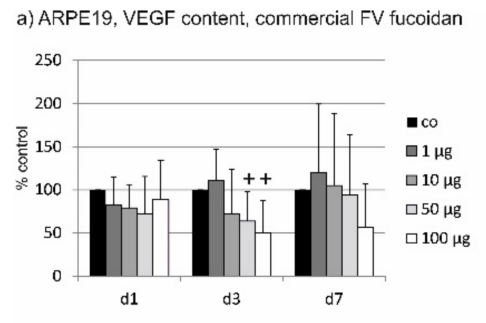

d) primary RPE, VEGF content, commercial FV fucoidan

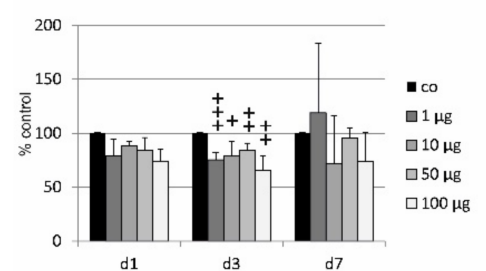

b) ARPE19, VEGF content, Heparin
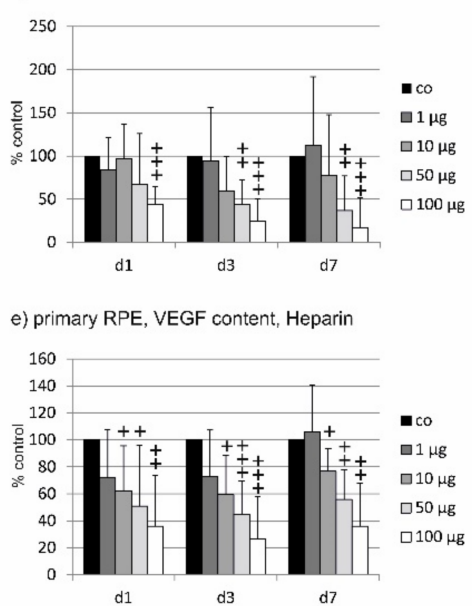

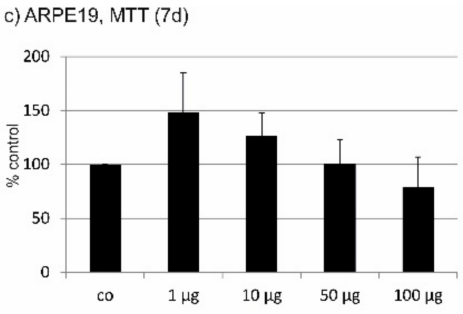

f) primary RPE, MTT (7d)

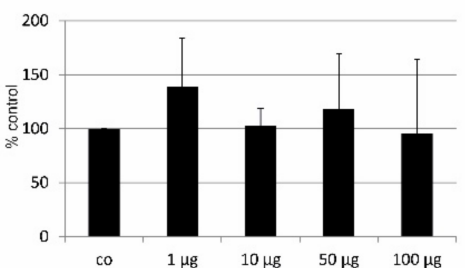

Figure 4. Effect of incubation time for vascular endothelial growth factor (VEGF) experiments. Commercially available fucoidan from Fucus vesiculosus was applied for 1 day (d1), 3 days (d3), and 7 days (d7), respectively, at indicated concentrations, to ARPE19 (a) or primary porcine retinal pigment epithelium (RPE) (d). In addition, heparin was tested on ARPE19 (b) and RPE cells (e). Cell viability was tested after 7 days (c, f). VEGF reduction was primarily seen after 3 days of incubation. Heparin showed a dose-dependent effect with similar significant reductions at all tested time points for concentrations of $10-100 \mu \mathrm{g} / \mathrm{mL}$. No toxic effect was seen after 7 days in either cell type. Significance was evaluated with Friedman's ANOVA and subsequent Student's $t$-test, $+p<0.05++p<0.01,+++p<0.001$ against the control $(n=4-6)$.

Based on these results, we investigated VEGF content after 3 days of incubation with fucoidan for all following experiments. VEGF content was normalized to cell viability and displayed in relation to an untreated control.

After 3 days, fucoidan from all algae tested showed a significant reduction in ANOVA. Fucoidan from Saccharina latissima showed a reduction of VEGF when applied in concentrations of 10-100 $\mu \mathrm{g} / \mathrm{mL}$ $(1 \mu \mathrm{g} / \mathrm{mL} 1.07 \pm 0.15 ; 10 \mu \mathrm{g} / \mathrm{mL} 0.76 \pm 0.11, p<0.01 ; 50 \mu \mathrm{g} / \mathrm{mL} 0.69 \pm 0.13, p<0.01 ; 100 \mu \mathrm{g} / \mathrm{mL} 0.46 \pm$ $0.21, p<0.001$ ) (Figure 5a). Fucoidan from Laminaria digitata significantly reduced VEGF content in all concentrations tested $(1 \mu \mathrm{g} / \mathrm{mL} 0.35 \pm 0.24 ; 10 \mu \mathrm{g} / \mathrm{mL} 0.18 \pm 0.17 ; 50 \mu \mathrm{g} / \mathrm{mL} 0.38 \pm 0.28 ; 100 \mu \mathrm{g} / \mathrm{mL}$ $0.14 \pm 0.11$; all $p<0.001$ ) (Figure 5b). Similarly, all concentrations of fucoidan from Fucus serratus showed significant inhibition of VEGF $(1 \mu \mathrm{g} / \mathrm{mL} 0.45 \pm 0.11 ; 10 \mu \mathrm{g} / \mathrm{mL} 0.54 \pm 0.28 ; 50 \mu \mathrm{g} / \mathrm{mL} 0.38 \pm$ $0.39 ; 100 \mu \mathrm{g} / \mathrm{mL} 0.05 \pm 0.11 ;$ all $p<0.001$ ) (Figure $5 \mathrm{c}$ ). Fucoidan from Fucus vesiculosus reduced VEGF at concentrations $1 \mu \mathrm{g} / \mathrm{mL}(0.50 \pm 0.22, p<0.001)$ and $50-100 \mu \mathrm{g} / \mathrm{mL}(50 \mu \mathrm{g} / \mathrm{mL} 0.33 \pm 0.29 ; 100 \mu \mathrm{g} / \mathrm{mL}$ $0.16 \pm 0.15$, both $p<0.001)$, but not $10 \mu \mathrm{g} / \mathrm{mL}(0.77 \pm 0.60)$ (Figure $5 \mathrm{~d})$. Fucoidan from Fucus distichus subsp. evanescens reduced VEGF at all concentrations tested $(1 \mu \mathrm{g} / \mathrm{mL} 0.41 \pm 0.22 ; 10 \mu \mathrm{g} / \mathrm{mL} 0.48 \pm 0.28$; $50 \mu \mathrm{g} / \mathrm{mL} 0.50 \pm 0.30 ; 100 \mu \mathrm{g} / \mathrm{mL} 0.04 \pm 0.05 ;$ all $p<0.001$ ) (Figure 5e).

In ARPE19 cells, all tested fucoidans reduced the amount of secreted VEGF, with the highest concentration $(100 \mu \mathrm{g} / \mathrm{mL})$ generally displaying the strongest effect. The differences between the different fucoidans are not as profound as those found in protective effects and are generally limited to effects seen at certain concentrations. LD fucoidan differs only slightly from FV or FS fucoidan (both $10 \mu \mathrm{g} / \mathrm{mL}, p<0.05)$ or from FE fucoidan $(10 \mu \mathrm{g} / \mathrm{mL}$ and $100 \mu \mathrm{g} / \mathrm{mL}$ both $p<0.05)$, while there were significant differences compared to SL fucoidan in all concentrations tested $(1-10 \mu \mathrm{g} / \mathrm{mL} p<0.001$; $50 \mu \mathrm{g} / \mathrm{mL} p<0.05 ; 100 \mu \mathrm{g} / \mathrm{mL} p<0.01)$. SL fucoidan significantly differed from FV fucoidan in all concentrations but $10 \mu \mathrm{g} / \mathrm{mL}(1 \mu \mathrm{g} / \mathrm{mL} p<0.001 ; 50 \mu \mathrm{g} / \mathrm{mL} p<0.05 ; 100 \mu \mathrm{g} / \mathrm{mL} p<0.01)$, while it differed 
from FE and FS fucoidan at concentrations of $1 \mu \mathrm{g} / \mathrm{mL}$ and $100 \mu \mathrm{g} / \mathrm{mL}$ (both $p<0.001$ ). FV fucoidan did not display any significant differences from FS fucoidan, and only at $100 \mu \mathrm{g} / \mathrm{mL}$ when compared to FE fucoidan $(p<0.05)$. Finally, FE and FS fucoidan did not display any significant differences (Table 3 ). Ranging the effect on VEGF secretion results in LD $>$ FS $>$ FE $>$ FV $>$ SL.

Table 3. Comparison of the effect of the different fucoidans at different concentrations on VEGF secretion in ARPE19 cells.

\begin{tabular}{ccccc}
\hline Compared Fucoidans & $\mathbf{1} \boldsymbol{\mu g} / \mathbf{m L}$ & $\mathbf{1 0} \boldsymbol{\mu g} / \mathbf{m L}$ & $\mathbf{5 0} \boldsymbol{\mu g} / \mathbf{m L}$ & $\mathbf{1 0 0} \boldsymbol{\mu g} / \mathbf{m L}$ \\
\hline LD vs. FV & $\mathrm{ns}$ & $p<0.05$ & $\mathrm{~ns}$ & $\mathrm{~ns}$ \\
LD vs. SL & $p<0.001$ & $p<0.001$ & $p<0.05$ & $p<0.01$ \\
LD vs. FE & $\mathrm{ns}$ & $p<0.05$ & $\mathrm{~ns}$ & $p<0.05$ \\
LD vs. FS & $\mathrm{ns}$ & $p<0.05$ & $\mathrm{~ns}$ & $\mathrm{~ns}$ \\
FV vs. SL & $p<0.001$ & $\mathrm{~ns}$ & $p<0.05$ & $p<0.01$ \\
FV vs. FE & $\mathrm{ns}$ & $\mathrm{ns}$ & $\mathrm{ns}$ & $p<0.05$ \\
FV vs. FS & $\mathrm{ns}$ & $\mathrm{ns}$ & $\mathrm{ns}$ & $\mathrm{ns}$ \\
SL vs. FE & $p<0.001$ & $\mathrm{~ns}$ & $\mathrm{~ns}$ & $p<0.001$ \\
SL vs. FS & $p<0.001$ & $\mathrm{~ns}$ & $\mathrm{~ns}$ & $p<0.001$ \\
FE vs. FS & $\mathrm{ns}$ & $\mathrm{ns}$ & $\mathrm{ns}$ & $\mathrm{ns}$ \\
\hline
\end{tabular}
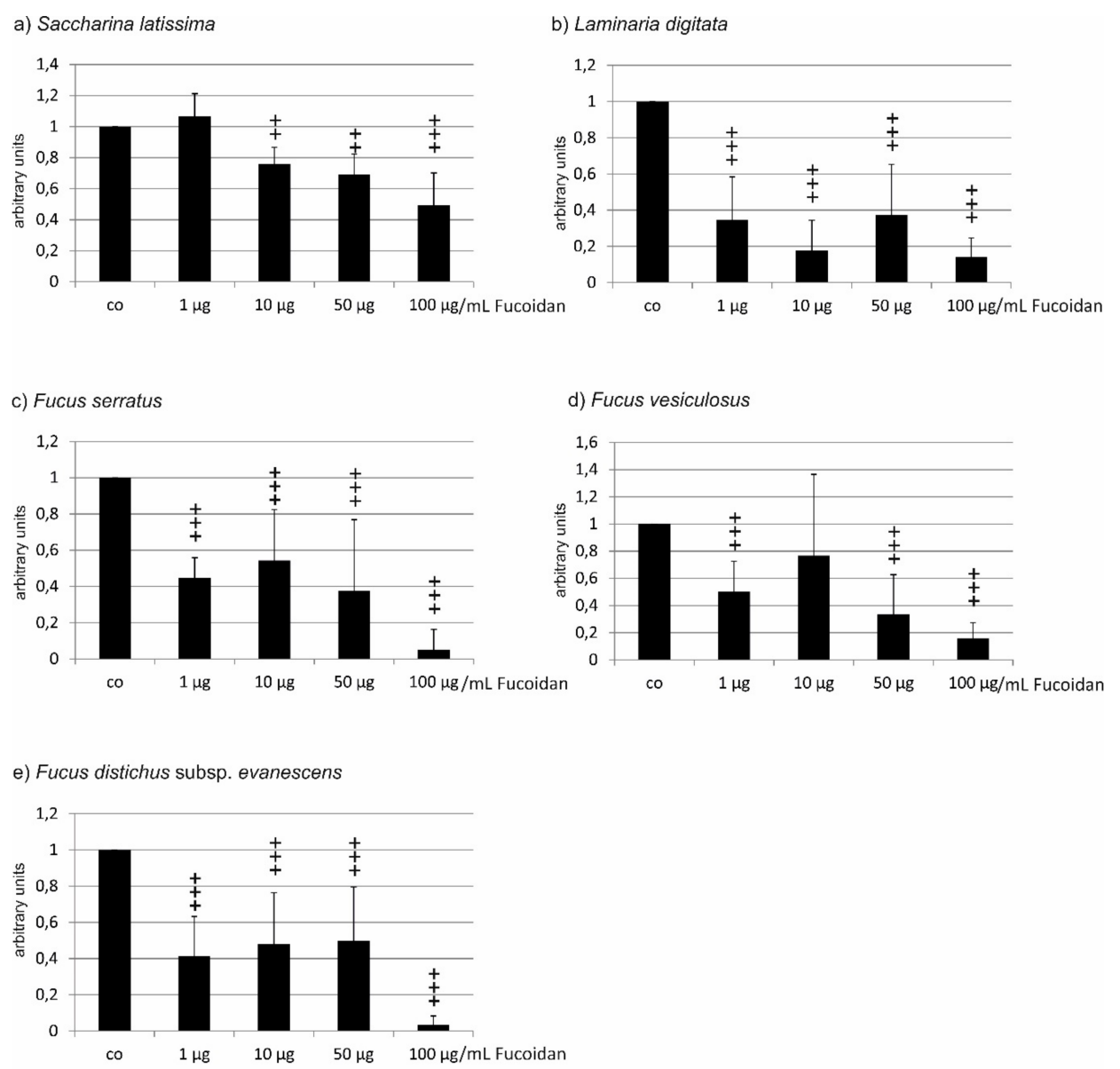

Figure 5. VEGF secretion in ARPE19 cells after incubation with different concentrations of fucoidan. (a) Saccharina latissima (SL), (b) Laminaria digitata (LD), (c) Fucus serratus (FS), (d) Fucus vesiculosus (FV), (e) Fucus distichus subsp. evanescens (FE). VEGF content was evaluated by ELISA and normalized to cell viability. Control $=1$. In ARPE19 cells, all fucoidans reduced VEGF content with the efficacy of LD > FS $>$ FE $>$ FV $>$ SL. Significance was evaluated with Friedman's ANOVA and subsequent Student's $t$-test, $++p<0.01,+++p<0.001$ compared to the control $(n=6-8)$. 


\subsubsection{Primary RPE}

The pretesting of Sigma fucoidan on cells for 1 day, 3 days, and 7 days led to the following. In primary porcine RPE cells, we found no significant reduction of VEGF content in the supernatant after 1 day $(1 \mu \mathrm{g} / \mathrm{mL} 79.25 \pm 15.04 \% ; 10 \mu \mathrm{g} / \mathrm{mL} 88.00 \pm 4.69 \% ; 50 \mu \mathrm{g} / \mathrm{mL} 84.25 \pm 11.87 \% ; 100 \mu \mathrm{g} / \mathrm{mL}$ $74.25 \pm 11.18 \%$ ). After 3 days, however, a significant reduction could be detected in ANOVA and was found in all concentrations assessed $(1 \mu \mathrm{g} / \mathrm{mL} 75.50 \pm 6.46 \%, p<0.001 ; 10 \mu \mathrm{g} / \mathrm{mL} 78.75 \pm 13.33 \%$, $p<0.05 ; 50 \mu \mathrm{g} / \mathrm{mL} 84.00 \pm 6.83 \% ; p<0.01 ; 100 \mu \mathrm{g} / \mathrm{mL} 65.5 \pm 13.92 \%, p<0.01)$. This effect was no longer seen after 7 days $(1 \mu \mathrm{g} / \mathrm{mL} 119.00 \pm 64.18 \% ; 10 \mu \mathrm{g} / \mathrm{mL} 71.75 \pm 44.70 \% ; 50 \mu \mathrm{g} / \mathrm{mL} 95.75 \pm$ $9.07 \%$ ); $100 \mu \mathrm{g} / \mathrm{mL} 73.75 \pm 27.21 \%$ ) (Figure $4 \mathrm{~d}$ ). In addition, we have tested the effect of heparin as a known VEGF binding control compound. At all three tested days, a significant reduction could be detected in ANOVA and concentrations of 10,50 , and $100 \mu \mathrm{g} / \mathrm{mL}$ heparin significantly reduced VEGF in a dose-dependent manner (day 1: $1 \mu \mathrm{g} / \mathrm{mL} 72.167 \pm 35.32 \% ; 10 \mu \mathrm{g} / \mathrm{mL} 62.17 \pm 33.44 \%, p<0.05$; $50 \mu \mathrm{g} / \mathrm{mL} 50.83 \pm 44.91 \%, p<0.05: 100 \mu \mathrm{g} / \mathrm{mL} 36.00 \pm 37.70 \%, p<0.01 ;$ day $3: 1 \mu \mathrm{g} / \mathrm{mL} 73.17 \pm 34.11 \%$; $10 \mu \mathrm{g} / \mathrm{mL} 59.60 \pm 28.78 \%, p<0.05 ; 50 \mu \mathrm{g} / \mathrm{mL} 44.50 \pm 25.11 \%, p<0.001 ; 100 \mu \mathrm{g} / \mathrm{m} .26 .33 \pm 31.40 \%, p<$ 0.001; day 7: $1 \mu \mathrm{g} / \mathrm{mL} 106.00 \pm 34.58 \% ; 10 \mu \mathrm{g} / \mathrm{mL} 76.60 \pm 16.88 \%, p<0.05 ; 50 \mu \mathrm{g} / \mathrm{mL} 55.80 \pm 22.00 \%$, $p<0.01 ; 100 \mu \mathrm{g} / \mathrm{mL} 36.00 \pm 31.98 \%, p<0.01$ ) (Figure 4e). No significant reduction of cell viability could be seen after 7 days $(1 \mu \mathrm{g} / \mathrm{mL} 139.17 \pm 45.20 \% ; 10 \mu \mathrm{g} / \mathrm{mL} 103.16 \pm 15.38 \% ; 118.00 \pm 51.54 \%$; $100 \mu \mathrm{g} / \mathrm{mL} 95.50 \pm 68.63 \%$ ) (Figure $4 \mathrm{f}$ ). Based on these results, we investigated VEGF content after 3 days for all following experiments. VEGF content was normalized to cell viability and displayed in relation to untreated controls.

After 3 days, fucoidan from Saccharina latissima reduced the VEGF content of RPE cells at a concentration of $10 \mu \mathrm{g} / \mathrm{mL}(0.77 \pm 0.17, p<0.01)$, while the other concentrations showed no significant effect $(1 \mu \mathrm{g} / \mathrm{mL} 0.97 \pm 0.07 ; 50 \mu \mathrm{g} / \mathrm{mL} 1.33 \pm 0.66 ; 100 \mu \mathrm{g} / \mathrm{mL} 0.92 \pm 0.27)$ (Figure 6a). None of the other fucoidans reduced VEGF content in RPE cells. Fucoidan from Laminaria digitata did not reduce VEGF secretion in primary porcine RPE cells in any concentration tested; however, a significant increase was detected in ANOVA, significantly increasing the VEGF signal at concentrations of $50 \mu \mathrm{g} / \mathrm{mL}$ and $100 \mu \mathrm{g} / \mathrm{mL}(1 \mu \mathrm{g} / \mathrm{mL} 1.27 \pm 0.57 ; 10 \mu \mathrm{g} / \mathrm{mL} 1.44 \pm 0.63 ; 50 \mu \mathrm{g} / \mathrm{mL} 1.59 \pm 0.43, p<0.01 ; 1.58 \pm 0.24$, $p<0.001$ ) (Figure $5 b$ ). Fucoidan from Fucus serratus displayed no significant influence on VEGF secretion in primary porcine RPE at any concentration tested $(1 \mu \mathrm{g} / \mathrm{mL} 0.96 \pm 0.08 ; 10 \mu \mathrm{g} / \mathrm{mL} 1.05 \pm$ $0.28 ; 50 \mu \mathrm{g} / \mathrm{mL} 1.14 \pm 0.38 ; 100 \mu \mathrm{g} / \mathrm{mL} 1.40 \pm 0.64$ ) (Figure 6c). Fucoidan from Fucus vesiculosus did not reduce VEGF in any tested concentration but, similar to LD fucoidan, displayed a significant increase in ANOVA testing, increasing the VEGF signal at concentrations of 50 and $100 \mu \mathrm{g} / \mathrm{mL}(1 \mu \mathrm{g} / \mathrm{mL} 1.28 \pm$ $0.62 ; 10 \mu \mathrm{g} / \mathrm{mL} 1.97 \pm 1.46 ; 50 \mu \mathrm{g} / \mathrm{mL} 1.78 \pm 0.44, p<0.001 ; 100 \mu \mathrm{g} / \mathrm{mL} 1.74 \pm 0.52, p<0.01$ ) (Figure $6 \mathrm{~d}$ ). Fucoidan from Fucus distichus subsp. evanescens displayed similar results. While no reduction of VEGF content could be seen at any tested concentration, significant differences could be detected in ANOVA, with $50 \mu \mathrm{g} / \mathrm{mL}$ and $100 \mu \mathrm{g} / \mathrm{mL}$ displaying an increase in VEGF content $(1 \mu \mathrm{g} / \mathrm{mL} 1.31 \pm 0.59$; $10 \mu \mathrm{g} / \mathrm{mL} 1.81 \pm 1.18 ; 50 \mu \mathrm{g} / \mathrm{mL} 2.02 \pm 0.98, p<0.05 ; 100 \mu \mathrm{g} / \mathrm{mL} 1.67 \pm 0.43, p<0.01$ ) (Figure 6e).

In primary RPE cells, only Saccharina latissima showed a reductive effect on VEGF content in the supernatant. When comparing the different fucoidans, significant differences were only found between SL and LD fucoidan (at a concentration of $10 \mu \mathrm{g} / \mathrm{mL}$ ) and between FV and FS fucoidan (at a concentration of $50 \mu \mathrm{g} / \mathrm{mL}$ ) (Table 4). 
a) Saccharina latissima

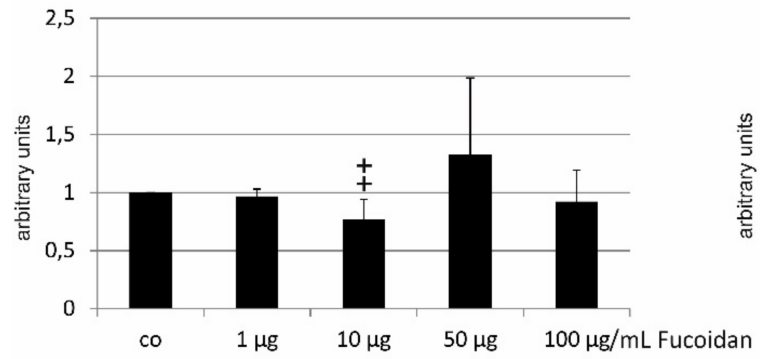

b) Laminaria digitata

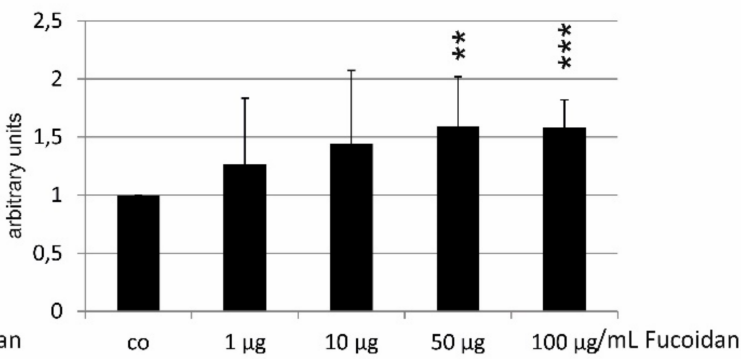

c) Fucus serratus

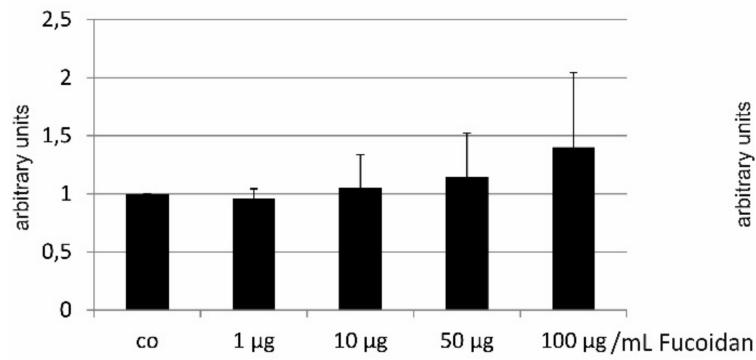

d) Fucus vesiculosus

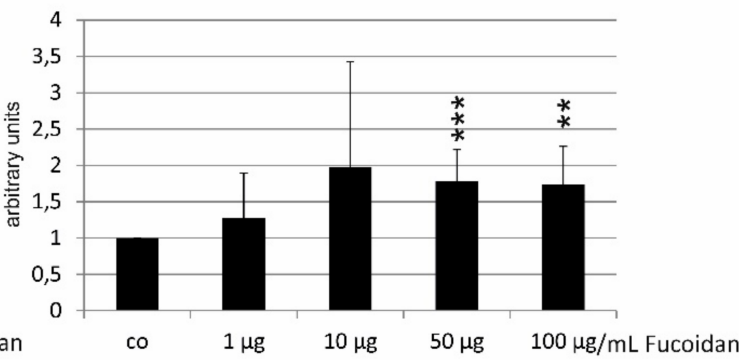

e) Fucus distichus subsp. evanescens

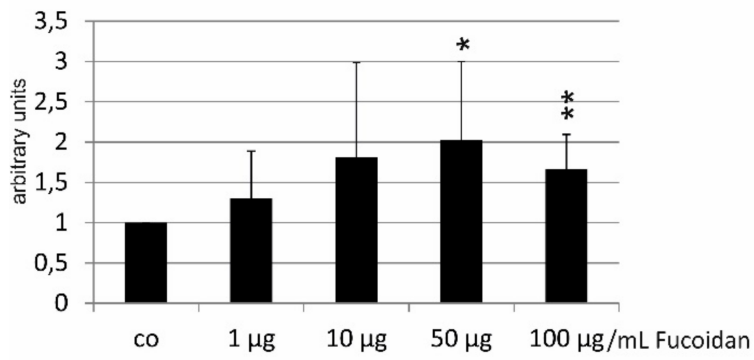

Figure 6. VEGF secretion of primary porcine RPE cells after incubation with different concentrations of fucoidan from (a) Saccharina latissima (SL), (b) Laminaria digitata (LD), (c) Fucus serratus (FS), (d) Fucus vesiculosus (FV), (e) Fucus distichus subsp. evanescens (FE). VEGF content was evaluated in ELISA and normalized to cell viability. Control $=1$. In RPE cells, only SL fucoidan reduced the VEGF content of RPE cells $(10 \mu \mathrm{g} / \mathrm{mL})$, while LD, FV, and FE induced a higher signal at concentrations of 50 and $100 \mu \mathrm{g} / \mathrm{mL}$. Significance was evaluated with Friedman's ANOVA and subsequent Student's $t$-test, $+p<0.05$ reduction compared to the control, ${ }^{*} p<0.05,{ }^{* *} p<0.01$ and ${ }^{* *} p<0.001(n=7)$.

Table 4. Comparison of the effect of different fucoidans at different concentrations on VEGF secretion in primary porcine RPE cells.

\begin{tabular}{ccccc}
\hline Compared Fucoidans & $\mathbf{1} \boldsymbol{\mu g} / \mathbf{m L}$ & $\mathbf{1 0} \boldsymbol{\mu g} / \mathbf{m L}$ & $\mathbf{5 0} \boldsymbol{\mu g} / \mathbf{m L}$ & $\mathbf{1 0 0} \boldsymbol{\mu g} / \mathbf{m L}$ \\
\hline LD vs. FV & $\mathrm{ns}$ & $\mathrm{ns}$ & $\mathrm{ns}$ & $\mathrm{ns}$ \\
LD vs. SL & $\mathrm{ns}$ & $p<0.05$ & $\mathrm{~ns}$ & $\mathrm{~ns}$ \\
LD vs. FE & $\mathrm{ns}$ & $\mathrm{ns}$ & $\mathrm{ns}$ & $\mathrm{ns}$ \\
LD vs. FS & $\mathrm{ns}$ & $\mathrm{ns}$ & $\mathrm{ns}$ & $\mathrm{ns}$ \\
FV vs. SL & $\mathrm{ns}$ & $\mathrm{ns}$ & $\mathrm{ns}$ & $\mathrm{ns}$ \\
FV vs. FE & $\mathrm{ns}$ & $\mathrm{ns}$ & $\mathrm{ns}$ & $\mathrm{ns}$ \\
FV vs. FS & $\mathrm{ns}$ & $\mathrm{ns}$ & $\mathrm{ns}$ & $\mathrm{ns}$ \\
SL vs. FE & $\mathrm{ns}$ & $\mathrm{ns}$ & $\mathrm{ns}$ & $\mathrm{ns}$ \\
SL vs. FS & $\mathrm{ns}$ & $\mathrm{ns}$ & $\mathrm{ns}$ & $\mathrm{ns}$ \\
FE vs. FS & $\mathrm{ns}$ & $\mathrm{ns}$ & & $\mathrm{ns}$ \\
\hline
\end{tabular}




\subsection{Binding Affinity to VEGF}

In the pathogenesis of the exudative form of AMD, VEGF is an important factor [5,6]. VEGF inhibitors are currently used as a therapy standard [11]. As has been known for a long time that heparin and other sulfated polysaccharides have a high affinity for VEGF [20], fucoidans may not only reduce the secretion of VEGF but also directly antagonize its actions. Therefore, we investigated the binding affinity of fucoidans to VEGF in comparison to heparin, and aimed to identify those fucoidans with the strongest binding affinity to VEGF.

In the competitive VEGF binding assay used, the replacement of biotinylated heparin by the test compound was measured. At a concentration of $0.5 \mu \mathrm{g} / \mathrm{mL}$, maximum binding of biotinylated heparin was achieved (data not shown). By adding increasing concentrations of unlabeled heparin, the detection of biotinylated heparin decreased (data not shown). As expected, incubation with a mixture of $0.5 \mu \mathrm{g} / \mathrm{mL}$ heparin and $0.5 \mu \mathrm{g} / \mathrm{mL}$ biotinylated heparin reduced the signal to $49.96 \%( \pm 7.28)$ and thus the binding of biotinylated heparin to VEGF. All five fucoidans showed a significant affinity to VEGF compared to the control, tested in ANOVA and subsequent testing (SL $26.13 \pm 13.46 \%$; LD $28.57 \pm 13.20 \%$; FS $10.63 \pm 6.43 \%$; FV $21.27 \pm 4.69 \%$ and FE $16.97 \pm 9.91 \%$ ) (Figure 7). Moreover, the three Fucus fucoidans bound significantly more strongly to VEGF than heparin $(p<0.01)$ (Table 5). Although FS and FE showed a slightly higher affinity, there were no significant differences between the five fucoidans (Table 5).

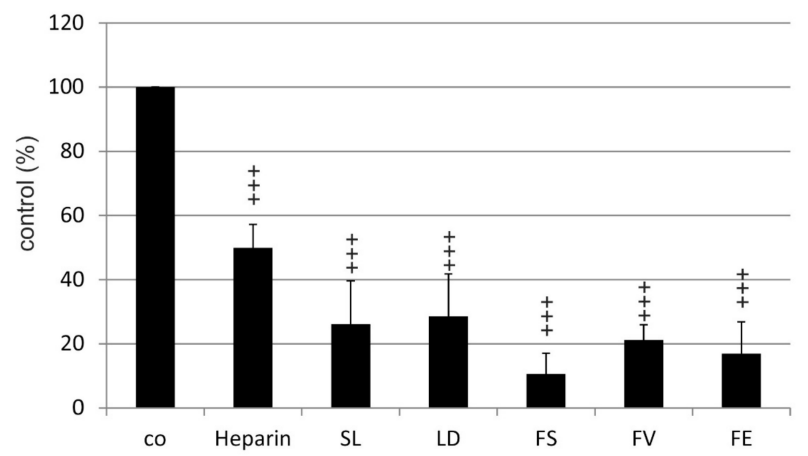

Figure 7. VEGF binding affinity of fucoidans from Saccharina latissima (SL), Laminaria digitata (LD), Fucus serratus (FS), Fucus vesiculosus (FV), Fucus distichus subsp. evanescens (FE), and of heparin. Significance was evaluated with Friedman's ANOVA and subsequent Student's $t$-test, $+++p<0.001$ compared to control (biotinylated heparin).

Table 5. Comparison of the VEGF binding affinity of fucoidans and heparin.

\begin{tabular}{cc}
\hline Compared Substances & Significance \\
\hline Heparin vs. FV & $p<0.01$ \\
Heparin vs. FS & $p<0.01$ \\
Heparin vs. FE & $p<0.01$ \\
Heparin vs. LD & $\mathrm{ns}$ \\
Heparin vs. SL & $\mathrm{ns}$ \\
LD vs. FV & $\mathrm{ns}$ \\
LD vs. SL & $\mathrm{ns}$ \\
LD vs. FE & $\mathrm{ns}$ \\
LD vs. FS & $\mathrm{ns}$ \\
FV vs. SL & $\mathrm{ns}$ \\
FV vs. FE & $\mathrm{ns}$ \\
FV vs. FS & $\mathrm{ns}$ \\
SL vs. FE & $\mathrm{ns}$ \\
SL vs. FS & $\mathrm{ns}$ \\
FE vs. FS & $\mathrm{ns}$ \\
\hline
\end{tabular}




\section{Discussion}

Fucoidans are of great interest to biomedical research, especially considering their possible application in age-related macular degeneration [4]. However, the effects of fucoidans can profoundly vary depending on their origin and method of extraction. Therefore, generalized statements about their activities should be avoided.

In this study, we have compared fucoidans from five different brown algae species harvested in summer and obtained from the same supplier (Coastal Research \& Management, Kiel, Germany). The preparation of the algal material as well as the extraction and purification of the fucoidans were performed in parallel according to a standardized procedure. Therefore, this study is well equipped to reliably examine the effects of fucoidans from different algal species. The aim was to compare the beneficial properties of fucoidans with regard to age-related macular degeneration.

In our study, we focused on two major factors important for the development of age-related macular degeneration, i.e., oxidative stress and VEGF. While interference with these is without doubt of great interest, we are aware that other activities, e.g., anticomplementary, anti-inflammatory effects, or influence on lipid metabolism, are also potentially beneficial for impairing AMD pathogenesis and are of high interest for further testing.

We have previously shown that OMM-1 cells are protected by commercially available fucoidan [17]. In contrast to uveal melanoma cells, RPE cells are intrinsically strongly protected against oxidative stress [18], so we tested oxidative stress protection both in OMM-1 cell lines, which we know could be protected by fucoidans, having demonstrated this for commercial fucoidan from Fucus vesiculosus [17], as well as the RPE cell line ARPE19. All five fucoidans protected OMM-1 cells from oxidative stress, confirming our previous results. However, fucoidans can differ in their properties depending on the test system or the cell types due to distinct cellular and molecular pathways. A major task of RPE cells is oxidative stress protection [18] and, as mentioned above, they are naturally highly resistant to oxidative stress. ARPE19 cells, as an RPE cell line, consequently behaved differently from OMM-1 cells, not only concerning their susceptibility to oxidative stress itself, but also their reaction to fucoidans. In contrast to OMM-1 cells, only SL fucoidan displayed a protection of cell viability, while FE and FS fucoidan even exacerbated the effect.

Little is known about oxidative stress pathways in uveal melanoma cells, but an increased susceptibility due to the reduction of superoxide dismutase activity in uveal melanoma cells has been described [21]. There is a debate about the direct reactive oxygen species (ROS) scavenging effect of fucoidans. The ROS scavenging potency of fucoidan has been described in several publications [22-25], but it has recently been demonstrated in cell-free systems that these measured effects are mainly due to co-extracted phenolic and terpenoid compounds in the fucoidan preparations $[15,26]$. Generally, the scavenging effect of fucoidan against hydrogen peroxide has been described to be rather weak $[24,25]$. Our results even suggest that the in vitro ROS scavenging activity may be irrelevant as, in contrast to SL and LD, the three Fucus fucoidans showed an ROS scavenging effect (manuscript in preparation) but did not protect ARPE19 cells from oxidative stress.

However, independent of all of the results from simple cell-free assays, fucoidans may exhibit antioxidative activity by cellular effects. Accordingly, fucoidan has been shown to increase the expression of superoxide dismutase (SOD) in several experimental models and activate the transcription factor nuclear factor erythroid 2-like 2 (Nrf2), the "master regulator" of the antioxidative stress response [27-32]. Both the overall protective effect of our fucoidans on OMM-1 and the limited protective effect on ARPE19 cells (only found for Saccharina latissima fucoidan) could be explained via these pathways. As mentioned above, uveal melanoma cells have been described to have a reduced SOD activity [21]. Hence, the SOD-inducing effect of fucoidans could protect these cells against an oxidative stress insult. In contrast, RPE cells have a high intrinsic stress response level mediated by Nrf2 [18]. Indeed, knock-out of Nrf2 renders RPE cells highly susceptible to oxidative stress insults [33] and Nrf2 knock-out mice develop AMD-like features at an older age [34]. It is feasible that these protective pathways are already at maximum efficacy, so that any further enhancement by fucoidans 
may be impossible. Therefore, the different effects of fucoidans on the two cell lines are assumed to be due to distinct impacts on the respective cellular pathways. Further research needs to be conducted to elucidate these pathways. It should be noted, however, that oxidative stress protection in AMD is not only needed for (the rather resistant) RPE cells, but also for the rather fragile photoreceptor cells [35]. Therefore, the effect of fucoidans on oxidative stress-induced photoreceptor cell death should also be evaluated in further studies.

A major contributor to the pathology of wet AMD is the growth factor VEGF, and its inhibition is the only current treatment option for AMD patients. We have previously shown that commercially obtained fucoidan from Fucus vesiculosus additively reduced VEGF expression when co-applied with the VEGF inhibitor bevacizumab [3]. On the molecular level, the interaction of fucoidan with VEGF differs profoundly from that of the current therapeutic anti-VEGF molecules. VEGF antibody-derived compounds bevacizumab and ranibizumab, as well as the fusion protein aflibecept, interact with specific amino acids in the receptor-binding domain of VEGF, causing a steric inhibition of the binding of VEGF to its receptor [36], with differences in affinities between the compounds [37]. The interaction of fucoidan and other heparin-related compounds is complex, however, depending on features such as sulfation and molecular weight $[38,39]$. Furthermore, fucoidan has been shown to also have a binding affinity to VEGF receptors and to facilitate the internalization of VEGF receptors, blocking the binding and in-vitro functions of VEGF $[38,40,41]$.

In our current study, we were able to demonstrate antagonization as well as a reduction of VEGF secretion in ARPE19 cells, in which all five fucoidans were effective. In primary porcine RPE cells, however, only SL displayed a significant effect.

Fucoidan was found to influence Stat3-regulated promoters, which includes the promoter of VEGF [42]. But it should be noted that we have previously shown that in unchallenged primary RPE cells, Stat3 is not involved in constitutive VEGF expression [43]. Therefore, this mechanism of fucoidan-mediated VEGF reduction is not feasible. We have also previously shown that VEGF is positively regulated in an autocrine way via the VEGFR-2 [43,44], whereby fucoidan has been shown to bind to VEGF165 and to competitively inhibit the interaction of VEGF with VEGFR2 [39,40]. This pathway has been suggested to be involved in VEGF reduction mediated by fucoidan $[3,40]$. Such an extracellular mode of action for fucoidans is now supported by the binding of the five fucoidans to VEGF. Their affinity was significantly higher than that of heparin, whereas heparan sulfate was not able to reduce the binding of biotinylated heparin to VEGF. Interaction of VEGF with heparin sulfate on the cell surface was found to be involved in effective VEGFR2 activation [45]. Thus, the fucoidans may competitively prevent this interaction and thus attenuate signaling through VEGFR2, resulting in reduced VEGF expression and secretion. In line with this assumed mode of action are the findings that the intraocular injection of heparan sulfate or heparin in mice eyes with aberrant angiogenesis results in reduced neovascularization [46]. Given the even higher affinity to VEGF of fucoidans, this seems promising.

The amount of VEGF secreted by primary RPE cells in this study was much higher than that of ARPE19 cells (596.72 pg/h for primary RPE vs. 17.35 pg/h for ARPE19; factor 34.4). In the presence of such high VEGF concentrations, the VEGF antagonizing mode of action obviously became ineffective, explaining the discrepant results in ARPE19 cells and RPE cells. Therefore, the effect of SL on VEGF secretion in primary RPE cells is even more remarkable.

Our data clearly show a positive effect of the tested fucoidans in terms of oxidative stress protection and VEGF inhibition, with the most promising fucoidan extracted from Saccharina latissima. Among the tested fucoidans, SL had the highest degree of sulfation, the highest molecular weight, and the highest degree of purity (under submission). But these parameters cannot explain its superiority or the ranking of the other fucoidans. Fucoidans from Saccharina latissima have been previously shown to be highly biologically active compared to those from other brown algae species $[15,16]$. Furthermore, in line with our finding concerning VEGF inhibition, fucoidans from Saccharina latissima have been shown to inhibit angiogenesis in tumor models [47]. However, it seems too early to decide that the 
other fucoidans are not worth further investigation. Other activities beneficial for AMD therapy should be regarded as well. Further preclinical and clinical research is warranted, but fucoidans may be a potential treatment option for age-related macular degeneration. To develop potential therapeutics from fucoidan, in addition to finding the most suitable source and a sustainable and reliable harvest and extraction method, bioavailability and application forms need to be tested.

In addition, VEGF secretion and oxidative stress are also involved in the pathomechanisms of diabetic retinopathy [48,49]. Therefore, fucoidans may also be of great interest for diabetic patients, especially considering that fucoidan may also reduce blood glucose levels and ameliorate hypertension [4].

In conclusion, we compared fucoidan from five brown algae species in terms of three activities that are considered promising for the treatment of AMD, i.e., their capacity for oxidative stress protection, inhibition of VEGF secretion, and binding affinity to VEGF. Based on these three basic parameters, the fucoidan from Saccharina latissima turned out to be most suitable for further investigations.

\section{Material and Methods}

\subsection{Cell Culture}

The uveal melanoma cell line OMM-1 [50] was a kind gift from Dr. Sarah Coupland and was cultivated in an appropriate medium (RPMI, Merck, Darmstadt, Germany, supplemented with 10\% fetal calf serum and 1\% penicillin/streptomycin). The immortal human RPE cell line ARPE19 was obtained from American Type Culture Collection (ATCC) and cultivated in an appropriate medium (Dulbecco's Modified Eagle's Medium (DMEM), supplemented with penicillin/streptomycin (1\%), non-essential amino acids (1\%), 4-(2-hydroxyethyl)-1-piperazineethanesulfonic acid (HEPES) (25\%), and $10 \%$ fetal calf serum).

Primary RPE cells were prepared as previously described [51,52]. In brief, RPE cells were harvested from cleaned porcine eyes by trypsin incubation and cultivated in an appropriate medium (DMEM, HyClone, Thermo Fisher Sc., Bremen, Germany, supplemented with penicillin/streptomysin (1\%), HEPES (25\%), non-essential amino acids (1\%), all Merck, Darmstadt, Germany, and 10\% fetal calf serum, Linaris GmbH, Wertheim-Bettingen, Germany). RPE and ARPE19 cells were used at confluence and OMM-1 at $80 \%$ confluence for further experimentation.

\subsection{Fucoidans}

Fucoidans were extracted from dried stocks of the species Saccharina latissima (SL; Atlantic, Funningsfjord, Faroe Island), Fucus vesiculosus (FV; Baltic, Kiel Bay, Germany), Laminaria digitata (LD; Atlantic; Churchbay, Island ), Fucus distichus subsp. evanescens (FE; Baltic, Kiel Cana, Germany), and Fucus serratus (FS; Baltic, Kiel Bay, Germany), all harvested in summer and provided by Coastal Research \& Management, Kiel, Germany. The fucoidans were extracted as previously described [53]. Briefly, the pulverized algal material was defatted by Soxhlet extraction with $99 \%(v / v)$ ethanol, and was then extracted with aqueous $2 \%$ calcium chloride for $2 \mathrm{~h}$ at $85{ }^{\circ} \mathrm{C}$ under reflux conditions. The supernatants of the raw extracts were concentrated and precipitated with ice-cold ethanol in a final concentration of $60 \%(w / w)$. After centrifugation, the sediments were dissolved in demineralized water, dialyzed, and lyophilized. In addition, commercially available fucoidan from Sigma (Sigma-Aldrich, Deisenhofen, Germany, F8190) was used. Fucoidan was solved in Ampuwa bidest (Fresenius, Schweinfurt, Germany), and then further diluted with appropriate cell medium for the cell experiments and phosphate buffered saline (PBS) for the VEGF binding assay, filtered through a $0.2 \mu \mathrm{m}$ filter (Sarstedt, Nümbrecht, Germany), and applied to the cells in final concentrations of 1, 10, 50, and $100 \mu \mathrm{g} / \mathrm{mL}$. 


\subsection{Oxidative Stress}

\subsubsection{OMM-1}

OMM-1 cells were treated with hydrogen peroxide $\left(\mathrm{H}_{2} \mathrm{O}_{2}\right)$ to induce oxidative stress-related cell death, as previously shown [17]. As OMM-1 is a cancer cell line that may change its characteristics during subculture, we evaluated the appropriate concentrations of $\mathrm{H}_{2} \mathrm{O}_{2}$ resulting in approximately $50 \%$ cell viability. In order to assess this, OMM- 1 cells were treated with different concentrations (100, 200, 400, $1000 \mathrm{mM}$ ) of $\mathrm{H}_{2} \mathrm{O}_{2}$ for $24 \mathrm{~h}$ and cell viability was investigated by MTS assay (see below). To investigate the potential protective effects of the different fucoidans, a concentration of $1 \mathrm{mM} \mathrm{H}_{2} \mathrm{O}_{2}$ was chosen. Cells were treated with fucoidan $(1,10,50$, and $100 \mu \mathrm{g} / \mathrm{mL}) 30 \mathrm{~min}$ prior to the application of $\mathrm{H}_{2} \mathrm{O}_{2}$.

\subsubsection{ARPE19}

Corresponding experiments to find the appropriate $\mathrm{H}_{2} \mathrm{O}_{2}$ concentration for ARPE19 cells revealed that none of the tested concentrations of $\mathrm{H}_{2} \mathrm{O}_{2}(100 \mu \mathrm{M}, 200 \mu \mathrm{M}, 400 \mu \mathrm{M}, 1000 \mu \mathrm{M})$ induced a cell death of about $50 \%$ after $24 \mathrm{~h}$, as detected by MTS assay. In addition, the cell death rate was highly variable after $\mathrm{H}_{2} \mathrm{O}_{2}$ incubation (see results). Therefore, we tested tert-Butyl hydroperoxide (TBHP), a more stable inducer of oxidative stress in RPE cells [33], at concentrations of $100 \mu \mathrm{M}, 250 \mu \mathrm{M}$, and $500 \mu \mathrm{M}$, for $24 \mathrm{~h}$ and investigated cell viability by MTS assay, as described below. In order to investigate the potential protective effect of the different fucoidans, a concentration of $500 \mu \mathrm{M}$ TBHP was chosen. Cells were treated with fucoidan $30 \mathrm{~min}$ prior to the insult.

\subsection{Methyl Thiazolyl Tetrazolium (MTT) Assay}

MTT assay is a common method in cell research [54] and was conducted as previously described [3]. In brief, after treatment with the fucoidans, the cells were washed and incubated with $0.5 \mathrm{mg} / \mathrm{mL}$ MTT (dissolved in DMEM without phenol red). After removal and further washing of the cells, cells were lysed with dimethyl sulfoxide (DMSO) and the absorbance was measured at $550 \mathrm{~nm}$ with a spectrometer (Elx800, BioTek, Bad Friedrichshall, Germany).

\subsection{MTS Assay}

The MTS assay is a commercially available viability assay and was used according to the manufacturers' instructions (CellTiter 96 ${ }^{\circledR}$ AQueous One Solution Cell Proliferation Assay (Promega, Mannheim, Germany)). The cell viability assay was performed in 96 well plates in phenol red-free medium with the same supplements described above. In each well, $20 \mu \mathrm{L}$ of MTS solution was added for $1 \mathrm{~h}$.

\subsection{VEGF ELISA}

VEGF was detected in the supernatants of ARPE19 and primary RPE cells using commercially available ELISA kits (R\&D Systems, Wiesbaden, Germany) according to the manufacturer's instructions. To establish the parameters of VEGF ELISA, we investigated time-dependent VEGF secretion in ARPE19 and primary RPE cells in the presence and absence of commercially available fucoidan from Fucus vesiculosus (Sigma-Aldrich, F8190) for 1 day, 3 days, and 7 days. A cell viability assay (MTT) was conducted after 7 days. According to these results, an incubation time of 3 days was chosen for experiments with the five different fucoidans. The medium was changed $24 \mathrm{~h}$ prior in ARPE19 cells and $4 \mathrm{~h}$ prior in primary RPE cells and the supernatant collected. Measured VEGF content was normalized for cell survival and is depicted in relation to that of untreated control cells. 


\subsection{Competitive VEGF Binding Assay}

The affinity to VEGF of the test compounds was investigated with a competitive VEGF-binding assay using biotinylated heparin. In addition to the fucoidans, heparin (EDQM, no. Y0001282, Strasbourg, France) was tested.

The wells of a 96-well Nunc-Immuno MaxiSorp microplate (Sigma-Aldrich, Deisenhofen, Germany) were coated with $0.1 \mu \mathrm{g}$ recombinant human VEGF 165 (R\&D Systems Cat. 293-VE/CF) dissolved in $100 \mu \mathrm{L}$ PBS overnight at $4{ }^{\circ} \mathrm{C}$. After washing with PBS, the coated wells were blocked for $90 \mathrm{~min}$ at $37^{\circ} \mathrm{C}$ with $100 \mu \mathrm{L}$ of $5 \mathrm{mg} / \mathrm{mL}$ bovine serum albumin (BSA, dissolved in PBS) and subsequently washed three times with PBS. During the blocking, $65 \mu \mathrm{L}$ of $1 \mu \mathrm{g} / \mathrm{mL}$ heparin, biotin conjugate (Merck, Darmstadt, Germany) in PBS, and $65 \mu \mathrm{L}$ of $1 \mu \mathrm{g} / \mathrm{mL}$ test compounds in PBS were preincubated at $4{ }^{\circ} \mathrm{C}$. For the blank and the $100 \%$ binding value, $100 \mu \mathrm{L}$ PBS and $100 \mu \mathrm{L}$ of $0.5 \mu \mathrm{g} / \mathrm{mL}$ biotinylated heparin in PBS, respectively, were preincubated at $4{ }^{\circ} \mathrm{C}$. Aliquots of $100 \mu \mathrm{L}$ of these solutions were pipetted into the coated microplate wells and incubated for $2 \mathrm{~h}$ at $37^{\circ} \mathrm{C}$ with gentle agitation. After three washing steps, $100 \mu \mathrm{L}$ of streptavidin alkaline phosphate conjugate (Southern Biotech/, Birmingham, AL, USA, stock solution diluted 1:3000 with PBS) was incubated for $1 \mathrm{~h}$ at $37^{\circ} \mathrm{C}$ with gentle agitation. The next steps involved three washings with PBS and incubation with $100 \mu \mathrm{L}$ p-nitrophenyl phosphate substrate system (Sigma-Aldrich, Deisenhofen, Germany) for $30 \mathrm{~min}$ in the dark. The reaction was stopped by addition of $25 \mu \mathrm{L} 3 \mathrm{~N} \mathrm{NaOH}$, and the absorbance was measured at $405 \mathrm{~nm}$. Blank values in the absence of biotinylated heparin were subtracted from the measured values. The reduction of the binding of biotinylated heparin by the test compounds is indicated as a percentage in relation to the binding of the biotinylated heparin alone.

\subsection{Statistics}

All experiments testing fucoidans were independently repeated at least six times, experiments for establishing oxidative stress response were repeated at least three times, and the VEGF binding experiments were performed in duplicates on three different days. Statistics were calculated using Statistica 7 (Statsoft, Tulsa, OK, USA) and Microsoft Excel (Excel 2010, Microsoft, Redmond, WA, USA). A Friedman's ANOVA was performed, and, if a significant difference between groups was detected, a subsequent Student's $t$-test was conducted. A $p$ value of $<0.05$ was considered significant. All bars represent mean and standard deviation.

Author Contributions: Conceptualization, A.K. and S.A.; Methodology, A.K., P.D., S.A., K.S.B., S.N.; Software, A.K.; Validation, A.K., P.D., S.A., K.S.B. and S.N.; Formal Analysis, P.D., A.K., K.S.B., S.A., S.N.; Investigation, P.D., K.S.B.; Resources, J.R., A.K., S.A.; Data Curation, A.K., S.A.; Writing-Original Draft Preparation, A.K., S.A.; Writing-Review \& Editing, A.K., P.D., K.S.B., S.N., J.R., S.A.; Visualization, A.K.; Supervision, A.K., S.A., J.R.; Project Administration, A.K.; Funding Acquisition, A.K., J.R.

Funding: The research was funded by EU InterReg Deutschland-Denmark and the European Regional Development Fund, Project FucoSan, grant number 39-1.0-16. AK was funded by the Hermann-Wacker Foundation.

Acknowledgments: This study is part of the FucoSan-Health from the Sea project and is supported by EU InterReg Deutschland-Denmark and the European Regional Development Fund. We especially thank Coastal Research \& Management, Kiel, for the provision of the algae.

Conflicts of Interest: The authors declare no conflict of interest.

\section{References}

1. Li, B.; Lu, F.; Wei, X.; Zhao, R. Fucoidan: Structure and bioactivity. Molecules 2008, 13, 1671-1695. [CrossRef] [PubMed]

2. Fitton, J.H.; Stringer, D.N.; Karpiniec, S.S. Therapies from Fucoidan: An Update. Mar. Drugs 2015, 13, 5920-5946. [CrossRef] [PubMed]

3. Dithmer, M.; Fuchs, S.; Shi, Y.; Schmidt, H.; Richert, E.; Roider, J.; Klettner, A. Fucoidan reduces secretion and expression of vascular endothelial growth factor in the retinal pigment epithelium and reduces angiogenesis in vitro. PLoS ONE 2014, 9, e89150. [CrossRef] 
4. Klettner, A. Fucoidan as a potential therapeutic for major blinding diseases-A hypothesis. Mar. Drugs 2016, 14, E31. [CrossRef]

5. Miller, J.W. Age-related macular degeneration revisited-piecing the puzzle: The LXIX Edward Jackson memorial lecture. Am. J. Ophthalmol. 2013, 155, 1-35. [CrossRef] [PubMed]

6. Klettner, A. Age-related macular degeneration-biology and treatment. Med. Monatsschr. Pharm. 2015, 38, 258-264. [PubMed]

7. Bellezza, I. Oxidative Stress in Age-Related Macular Degeneration: Nrf2 as Therapeutic Target. Front. Pharmacol. 2018, 9, 1280. [CrossRef]

8. Copland, D.A.; Theodoropoulou, S.; Liu, J.; Dick, A.D. A Perspective of AMD Through the Eyes of Immunology. Invest. Ophthalmol. Vis. Sci. 2018, 59, AMD83-AMD92. [CrossRef]

9. Handa, J.T.; Cano, M.; Wang, L.; Datta, S.; Liu, T. Lipids, Oxidized Lipids, Oxidation-specific Epitopes, and Age-related Macular Degeneration. Biochim. Biophys. Acta 2017, 1862, 430-440. [CrossRef]

10. Toomey, C.B.; Johnson, L.V.; Bowes Rickman, C. Complement factor H in AMD: Bridging genetic associations and pathobiology. Prog. Retin. Eye Res. 2018, 62, 38-57. [CrossRef]

11. Schmidt-Erfurth, U.; Chong, V.; Loewenstein, A.; Larsen, M.; Souied, E.; Schlingemann, R.; Eldem, B.; Monés, J.; Richard, G.; Bandello, F. European Society of Retina Specialists. Guidelines for the management of neovascular age-related macular degeneration by the European Society of Retina Specialists (EURETINA). Br. J. Ophthalmol. 2014, 98, 1144-1167. [CrossRef]

12. Rofagha, S.; Bhisitkul, R.B.; Boyer, D.S.; Sadda, S.R.; Zhang, K.; SEVEN-UP Study Group. Seven-year outcomes in ranibizumab-treated patients in ANCHOR, MARINA, and HORIZON: A multicenter cohort study (SEVEN-UP). Ophthalmology 2013, 120, 2292-2299. [CrossRef]

13. Zarubina, A.V.; Gal-Or, O.; Huisingh, C.E.; Owsley, C.; Freund, K.B. Macular Atrophy Development and Subretinal Drusenoid Deposits in Anti-Vascular Endothelial Growth Factor Treated Age-Related Macular Degeneration. Invest. Ophthalmol. Vis. Sci. 2017, 58, 6038-6045. [CrossRef]

14. Moryak, V.K.; Kim, J.; Kim, E. Algal fucoidan: Structural and size-dependent bioactivities and their perspectives. Appl. Microbiol. Biotechnol. 2012, 93, 71-82. [CrossRef]

15. Schneider, T.; Ehrig, K.; Liewert, I.; Alban, S. Interference with the CXCL12/CXCR4 axis as potential antitumor strategy: Superiority of a sulfated galactofucan from the brown alga Saccharina latissima and fucoidan over heparins. Glycobiology 2015, 25, 812-824. [CrossRef]

16. Cumashi, A.; Ushakova, N.A.; Preobrazhenskaya, M.E.; D'Incecco, A.; Piccoli, A.; Totani, L.; Tinari, N.; Morozevich, G.E.; Berman, A.E.; Bilan, M.I.; et al. A comparative study of the anti-inflammatory, anticoagulant, antiangiogenic, and antiadhesive activities of nine different fucoidans from brown seaweeds. Glycobiology 2007, 17, 541-552. [CrossRef]

17. Dithmer, M.; Kirsch, A.M.; Richert, E.; Fuchs, S.; Wang, F.; Schmidt, H.; Coupland, S.E.; Roider, J.; Klettner, A. Fucoidan does not exert anti-tumorigenic effects on uveal melanoma cell lines. Mar. Drugs 2017, 15, 193. [CrossRef]

18. Klettner, A. Oxidative stress induced cellular signaling in RPE cells. Front. Biosci. (Schol. Ed.) 2012, 4, 392-411. [CrossRef]

19. Karlsson, M.; Kurz, T. Attenuation of iron-binding proteins in ARPE-19 cells reduces their resistance to oxidative stress. Acta Ophthalmol. 2016, 94, 556-564. [CrossRef]

20. Folkman, J.; Shing, Y. Control of angiogenesis by heparin and other sulfated polysaccharides. Adv. Exp. Med. Biol. 1992, 313, 355-364.

21. Blasi, M.A.; Maresca, V.; Roccella, M.; Roccella, F.; Sansolini, T.; Grammatico, P.; Balestrazzi, E.; Picardo, M. Antioxidant pattern in uveal melanocytes and melanoma cell cultures. Invest. Ophthalmol. Vis. Sci. 1999, 40, 3012-3016.

22. Rupérez, P.; Ahrazem, O.; Leal, J.A. Potential antioxidant capacity of sulfated polysaccharides from the edible marine brown seaweed Fucus vesiculosus. J. Agric. Food Chem. 2002, 50, 840-845. [CrossRef]

23. Wang, J.; Zhang, Q.; Zhang, Z.; Li, Z. Antioxidant activity of sulfated polysaccharide fractions extracted from Laminaria japonica. Int. J. Biol. Macromol. 2008, 42, 127-132. [CrossRef]

24. Kim, E.A.; Lee, S.H.; Ko, C.I.; Cha, S.H.; Kang, M.C.; Kang, S.M.; Ko, S.C.; Lee, W.W.; Ko, J.Y.; Lee, J.H.; et al. Protective effect of fucoidan against AAPH-induced oxidative stress in zebrafish model. Carbohydr. Polym. 2014, 102, 185-191. [CrossRef] 
25. Abu, R.; Jiang, Z.; Ueno, M.; Okimura, T.; Yamaguchi, K.; Oda, T. In vitro antioxidant activities of sulfated polysaccharide ascophyllan isolated from Ascophyllum nodosum. Int. J Biol. Macromol. 2013, 59, 305-312. [CrossRef]

26. Lahrsen, E.; Liewert, I.; Alban, S. Gradual degradation of fucoidan from Fucus vesiculosus and its effect on structure, antioxidant and antiproliferative activities. Carbohydr. Polym. 2018, 192, 208-216. [CrossRef]

27. Wang, Y.Q.; Wei, J.G.; Tu, M.J.; Gu, J.G.; Zhang, W. Fucoidan Alleviates Acetaminophen-Induced Hepatotoxicity via Oxidative Stress Inhibition and Nrf2 Translocation. Int. J. Mol. Sci. 2018, 19, 4050. [CrossRef]

28. Ryu, M.J.; Chung, H.S. Fucoidan reduces oxidative stress by regulating the gene expression of HO-1 and SOD-1 through the Nrf2/ERK signaling pathway in HaCaT cells. Mol. Med. Rep. 2016, 14, 3255-3260. [CrossRef]

29. Kim, H.; Ahn, J.H.; Song, M.; Kim, D.W.; Lee, T.K.; Lee, J.C.; Kim, Y.M.; Kim, J.D.; Cho, J.H.; Hwang, I.K.; et al. Pretreated fucoidan confers neuroprotection against transient global cerebral ischemic injury in the gerbil hippocampal CA1 area via reducing of glial cell activation and oxidative stress. Biomed. Pharmacother. 2019, 109, 1718-1727. [CrossRef]

30. Vomund, S.; Schäfer, A.; Parnham, M.J.; Brüne, B.; von Knethen, A. Nrf2, the Master Regulator of Anti-Oxidative Responses. Int. J. Mol. Sci. 2017, 18, 2772. [CrossRef]

31. Foresti, R.; Bucolo, C.; Platania, C.M.; Drago, F.; Dubois-Randé, J.L.; Motterlini, R. Nrf2 activators modulate oxidative stress responses and bioenergetic profiles of human retinal epithelial cells cultured in normal or high glucose conditions. Pharmacol. Res. 2015, 99, 296-307. [CrossRef] [PubMed]

32. Pittalà, V.; Fidilio, A.; Lazzara, F.; Platania, C.B.M.; Salerno, L.; Foresti, R.; Drago, F.; Bucolo, C. Effects of Novel Nitric Oxide-Releasing Molecules against Oxidative Stress on Retinal Pigmented Epithelial Cells. Oxid. Med. Cell Longev. 2017, 2017, 1420892. [CrossRef] [PubMed]

33. Koinzer, S.; Reinecke, K.; Herdegen, T.; Roider, J.; Klettner, A. Oxidative Stress Induces Biphasic ERK1/2 Activation in the RPE with Distinct Effects on Cell Survival at Early and Late Activation. Curr. Eye Res. 2015, 40, 853-857. [CrossRef] [PubMed]

34. Tode, J.; Richert, E.; Koinzer, S.; Klettner, A.; von der Burchard, C.; Brinkmann, R.; Lucius, R.; Roider, J. Thermal Stimulation of the Retina Reduces Bruch's Membrane Thickness in Age Related Macular Degeneration Mouse Models. Transl. Vis. Sci. Technol. 2018, 7, 2. [CrossRef] [PubMed]

35. German, O.L.; Agnolazza, D.L.; Politi, L.E.; Rotstein, N.P. Light, lipids and photoreceptor survival: Live or let die? Photochem. Photobiol. Sci. 2015, 14, 1737-1753. [CrossRef]

36. Klettner, A.; Roider, J. Treating age-related macular degeneration - interaction of VEGF-antagonists with their target. Mini Rev. Chem. 2009, 9, 1127-1135. [CrossRef]

37. Platania, C.B.; Di Paola, L.; Leggio, G.M.; Romano, G.L.; Drago, F.; Salomone, S.; Bucolo, C. Molecular features of interaction between VEGFA and anti-angiogenic drugs used in retinal diseases: A computational approach. Front. Pharmacol. 2015, 6, 248. [CrossRef] [PubMed]

38. Hu, M.; Cui, N.; Bo, Z.; Xiang, F. Structural Determinant and Its Underlying Molecular Mechanism of STPC2 Related to Anti-Angiogenic Activity. Mar. Drugs 2017, 15, 48. [CrossRef]

39. Koyanagi, S.; Tanigawa, N.; Nakagawa, H.; Soeda, S.; Shimeno, H. Oversulfation of fucoidan enhances its anti-angiogenic and antitumor activities. Biochem. Pharmacol. 2003, 65, 173-179. [CrossRef]

40. Chen, H.; Cong, Q.; Du, Z.; Liao, W.; Zhang, L.; Yao, Y.; Ding, K. Sulfated fucoidan FP08S2 inhibits lung cancer cell growth in vivo by disrupting angiogenesis via targeting VEGFR2/VEGF and blocking VEGFR2/Erk/VEGF signaling. Cancer Lett. 2016, 382, 44-52. [CrossRef]

41. Narazaki, M.; Segarra, M.; Tosato, G. Sulfated polysaccharides identified as inducers of neuropilin-1 internalization and functional inhibition of VEGF165 and semaphorin3A. Blood 2008, 111, 4126. [CrossRef]

42. Rui, X.; Pan, H.F.; Shao, S.L.; Xu, X.M. Anti-tumor and anti-angiogenic effects of Fucoidan on prostate cancer: Possible JAK-STAT3 pathway. BMC Complement. Altern. Med. 2017, 17, 378. [CrossRef]

43. Klettner, A.; Westhues, D.; Lassen, J.; Bartsch, S.; Roider, J. Regulation of constitutive vascular endothelial growth factor secretion in retinal pigment epithelium/choroid organ cultures: $\mathrm{p} 38$, nuclear factor $\mathrm{\kappa B}$, and the vascular endothelial growth factor receptor-2/phosphatidylinositol 3 kinase pathway. Mol. Vis. 2013, 19, 281-291.

44. Klettner, A.; Kaya, L.; Flach, J.; Lassen, J.; Treumer, F.; Roider, J. Basal and apical regulation of VEGF-A and placenta growth factor in the RPE/choroid and primary RPE. Mol. Vis. 2015, 21, 736-748. 
45. Cébe Suarez, S.; Pieren, M.; Cariolato, L.; Arn, S.; Hoffmann, U.; Bogucki, A.; Manlius, C.; Wood, J.; Ballmer-Hofer, K. A VEGF-A splice variant defective for heparan sulfate and neuropilin-1 binding shows attenuated signaling through VEGFR-2. Cell. Mol. Life Sci. 2006, 63, 2067-2077. [CrossRef]

46. Nishiguchi, K.M.; Kataoka, K.; Kachi, S.; Komeima, K.; Terasaki, H. Regulation of pathologic retinal angiogenesis in mice and inhibition of VEGF-VEGFR2 binding by soluble heparan sulfate. PLoS ONE 2010, 5, e13493. [CrossRef]

47. Croci, D.O.; Cumashi, A.; Ushakova, N.A.; Preobrazhenskaya, M.E.; Piccoli, A.; Totani, L.; Ustyuzhanina, N.E.; Bilan, M.I.; Usov, A.I.; Grachev, A.A.; et al. Fucans, but not fucomannoglucuronans, determine the biological activities of sulfated polysaccharides from Laminaria saccharina brown seaweed. PLoS ONE 2011, 6, e17283. [CrossRef]

48. Platania, C.B.M.; Maisto, R.; Trotta, M.C.; D'Amico, M.; Rossi, S.; Gesualdo, C.; D’Amico, G.; Balta, C.; Herman, H.; Hermenean, A.; et al. Retinal and circulating miRNA expression patterns in diabetic retinopathy: An in silico and in vivo approach. Br. J. Pharmacol. 2019, in press. [CrossRef]

49. Platania, C.B.M.; Leggio, G.M.; Drago, F.; Salomone, S.; Bucolo, C. Computational systems biology approach to identify novel pharmacological targets for diabetic retinopathy. Biochem. Pharmacol. 2018, 158, 13-26. [CrossRef]

50. Luyten, G.P.; Naus, N.C.; Mooy, C.M.; Hagemeijer, A.; Kan-Mitchell, J.; Van Drunen, E.; Vuzevski, V.; De Jong, P.T.; Luider, T.M. Establishment and characterization of primary and metastatic uveal melanoma cell lines. Int. J. Cancer 1996, 66, 380-387. [CrossRef]

51. Wiencke, A.K.; Kiilgaard, J.F.; Nicolini, J.; Bundgaard, M.; Röpke, C.; La Cour, M. Growth of cultured porcine retinal pigment epithelial cells. Acta Ophthalmol. Scand. 2003, 81, 170-176. [CrossRef]

52. Klettner, A.; Roider, J. Comparison of bevacizumab, ranibizumab, and pegaptanib in citro: Efficiency and possible additional pathways. Invest. Ophthalmol. Vis. Sci. 2008, 49, 4523-4527. [CrossRef]

53. Ehrig, K.; Alban, S. Sulfated galactofucan from the brown alga Saccharina latissima-variability of yield, structural composition and bioactivity. Mar. Drugs 2014, 13, 76-101. [CrossRef]

54. Riss, T.L.; Moravec, R.A.; Niles, A.L.; Duellman, S.; Benink, H.A.; Worzella, T.J.; Minor, L. Cell Viability Assays. In Assay Guidance Manual [Internet]; Sittampalam, G.S., Coussens, N.P., Brimacombe, K., Grossman, A., Arkin, M., Auld, D., Austin, C., Baell, J., Bejcek, B., Caaveiro, J.M.M., et al., Eds.; (MD), Eli Lilly \& Company and the National Center for Advancing Translational Sciences: Bethesda, MD, USA, 2013.

(C) 2019 by the authors. Licensee MDPI, Basel, Switzerland. This article is an open access article distributed under the terms and conditions of the Creative Commons Attribution (CC BY) license (http://creativecommons.org/licenses/by/4.0/). 